\title{
ЭПИДЕМИОЛОГИЧЕСКИЙ ПЕРЕХОД И ЕГО ИНТЕРПРЕТАЦИИ
}

\author{
АНАТОЛИЙ ВИШНЕВСКИЙ
}

\begin{abstract}
Критический анализ теории эпидемиологического перехода (ЭП) А. Омрана и ее различных интерпретаций. Ставится под сомнение предложенная Омраном периодизация ЭП, с ней сопоставляется разграничение двух «эпидемиологических револючий» М. Терриса. Отмечается огромное всемирно-историческое значение ЭП как триггера и составной части демографического перехода в целом и обосновывается несогласие с трактовкой ЭП как составной части «санитарного перехода». Оспаривается конщепщия «кардиоваскулярной револючии». Предлагается метод графического представления ЭП и обсуждаются критерии его завершения. Обосновывается несогласие с представлениями о «первом», неолитическом, и «третьем», ожидаемом в будущем, ЭП, а также об «обратном» ЭП. Рассматриваются проблемы «догоняющего» ЭП в развивающихся странах.
\end{abstract}

Ключевые слова: эпидемиологический переход, эпидемиологическая револючия, демографический переход, санитарный переход, стадии эпидемиологического перехода, кардиоваскулярная революиия, вероятность умереть, средний возраст смерти.

Термин «эпидемиологический переход» (ЭП) впервые был введен в научный оборот Абделем Омраном в статье, опубликованной в 1971 г. (Omran 1971; Омран 1977), и с тех пор неразрывно связывается с его именем. Статья Омрана стала одной из наиболее цитируемых, что вызывает даже некоторое раздражение у части демографической аудитории, и появляются публикации, главная цель которых - доказать, что слишком частое упоминание имени Омрана не оправдано, а его заслуги преувеличены. Причины чрезмерного цитирования авторы одной из таких публикаций видят не в истинных заслугах Омрана, а в том, что «критики, ищущие новые модели или концептуальные схемы, нашли в Омране удобную отправную точку, мишень или мальчика для битья, чтобы выделить собственные концептуальные инновации и придать им вес» (Weisz, Olszynko-Gryn 2009: 323). Это - хороший совет всем, кто, в свою очередь, хочет прославиться, как Омран, и тоже стать «мальчиком для битья»: надо всего лишь выдвинуть идею, мимо которой не сможет пройти ни один исследователь, работающий в соответствующей области знания.

Справедливости ради следует отметить, что концепция Омрана достаточно часто получает и высокую оценку как «потенциально мощная основа для изучения заболеваемости и смертности среди населения, особенно для изучения исторических и международных вариаций» (Mackenbach 1994: 330). Видимо, не случайно схема Омрана используется как исходный пункт для новых теоретических конструкций, правда, порой сохраняющих довольно призрачную связь с исходной концепцией, - и тогда действительно возникает вопрос, не служит ли обращение к этой концепции всего лишь способом придать таким конструкциям дополнительный вес.

АНАТОЛИЙ ГРИГОРЬЕВИЧ ВИШНЕВСКИЙ (avishnevsky@hse.ru), НАЦИОНАЛЬНЫЙ ИССЛЕДОВАТЕЛЬСКИЙ УНИВЕРСИТЕТ «ВЫСШАЯ ШКОЛА ЭКОНОМИКИ», РОССИЯ.

СТАТЬЯ ПОДГОТОВЛЕНА В РАМКАХ ПРОЕКТА «ДЕМОГРАФИЧЕСКИЕ И МИГРАЦИОННЫЕ ПРОЦЕССЫ В РОССИИ В ИСТОРИЧЕСКОМ И МЕЖДУНАРОДНОМ КОНТЕКСТЕ В СВЕТЕ НОВЫХ МЕТОДОЛОГИЧЕСКИХ ПОДХОДОВ» ПРОГРАММЫ ФУНДАМЕНТАЛЬНЫХ ИССЛЕДОВАНИЙ ВШЭ, 2019 Г.

СТАТЬЯ ПОСТУПИЛА В РЕДАКЦИЮ В ИЮЛЕ 2020 Г. 
И столь же не случайно, что при знакомстве с подобными конструкциями возникают вопросы к их создателям, а иногда и к самому Омрану, о том, насколько надежен заложенный им фундамент и насколько плодотворны направления развития его идей, предлагаемые разными авторами.

\section{«ПЕРЕХОД》 ИЛИ «РЕВОЛЮЦИЯ»?}

Омран использовал термин «переход», следуя, по-видимому, традиции, созданной в 40-е годы XX века принстонскими демографами, которые ввели в оборот термин «демографический переход» (Notestein 1945: 40; Davis 1945). В свою очередь этот термин утвердился в конкуренции с появившимся намного ранее (в 1934 г.) термином «демографическая револющия» (Landry 2019). Еще в 1944 г. К. Дэвис писал о «демографической революции, неотделимой от промышленной революции» (Davis 1944: 57). Даже и позднее американские демографы в том же смысле иногда употребляли термин «vital revolution» (Freedman 1964).

Некоторые авторы, опираясь на французскую традицию, продолжали использовать термин «демографическая революция» и в дальнейшем (см., напр., (Pavlik 1964: 234-247; 1982; Павлик 1979; Вишневский 1973; 1976). Тем не менее в мировой литературе возобладал термин «демографический переход», хотя, по словам ван де Каа, это «ослабило историческую глубину и смысловое звучание термина» (Van de Kaa 2010). Новый термин восприняли и на родине Ландри, пусть и с некоторыми оговорками. Например, Ж.-К. Шенэ, автор фундаментального исследования демографического перехода, что недвусмысленно отражено в названии его книги (Chesnais 1986), все же замечает, что в той мере, в какой речь идет о совершенно особом, радикально новом этапе демографического развития, «термин «демографическая революция», немного подзабытый, кажется более удачным» (Chesnais 1986: 18).

Завершая наш краткий терминологический экскурс, заметим, что выражение «эпидемиологическая революция» иногда используется авторами, которые, возможно, вообще не знакомы с представлениями о демографическом или эпидемиологическом переходах. В качестве примера приведем статью под названием «Эпидемиологическая революция XX века». В этой статье, опубликованной в 2005 г., говорится о том, что «XX век характеризовался фантастическим увеличением продолжительности жизни и переходом от инфекционных к хроническим дегенеративным заболеваниям в качестве основных причин смерти» и «обсуждаются корни и причины этих эпидемиологических изменений» (De Flora et al. 2005: 892). Ссылок на Омрана в этой статье нет, его имя ни разу не упоминается.

Еще более интересный пример - использование термина «эпидемиологическая революция» Милтоном Террисом; мы рассмотрим его несколько ниже.

В целом в литературе преобладает термин «переход», хотя причины такого выбора на фоне повсеместного использования термина «революция» («промышленная революция», «научно-техническая революция» и др.) не вполне ясны. Наверно, нет смысла ломать копья из-за выбора слова, в этой статье оба термина используются как синонимы. Но кое-какие издержки с этим все же связаны. 


\section{ПОЧЕМУ «ЭПИДЕМИОЛОГИЧЕСКИЙ»?}

В словосочетании «эпидемиологический переход» вопросы нередко вызывает не только слово «переход», но и слово «эпидемиологический».

В демографической литературе была высказана и получила довольно широкое распространение точка зрения, согласно которой понятие эпидемиологический переход слишком узкое и не охватывает всех перемен, происходящих в наше время со здоровьем и смертностью.

В частности, утверждается, что у Омрана «понятие «эпидемиологический переход» используется для обозначения переходного периода, а не процесса изменений» (Frenk et al. 1991: 23), что звучит довольно туманно. Одно из исходных положений Омрана гласит, что «в период эпидемиологического перехода происходит длительный сдвиг, в результате чего пандемии инфекционных заболеваний в качестве основной причины заболеваемости и смертности постепенно уступают место дегенеративным и профессиональным заболеваниям» (Omran 1971: 516; Омран 1977: 64). Можно ли яснее обозначить, в чем заключается суть процесса, обозначаемого термином «эпидемиологический переход»?

Еще один - центральный - упрек заключается в том, что концепция эпидемиологического перехода не идет дальше рассмотрения «долгосрочного процесса изменения состояния здоровья общества, включая изменения структуры заболеваемости, инвалидности и смертности», тогда как необходимо рассматривать также «изменения в структуре организованного социального реагирования в связи с состоянием здоровья», переход в здравоохранении (health care transition) (Frenk et al. 1991: 23). При таком подходе, полагают авторы статьи, преодолевается кажущееся узким сведение происходящих перемен к эпидемиологическому переходу и становится возможной более широкая их трактовка как «перехода в здоровье» (health transition) (Там же) или «санитарного перехода» ${ }^{1}$.

Этот упрек также едва ли обоснован. Называя переход «эпидемиологическим», Омран имел в виду его главный смысловой результат - смену эпидемиологической картины, эпидемиологической модели заболеваемости и смертности - в этом, собственно, и заключалась суть перехода. Но это никак не значит, что он игнорировал «организованное социальное реагирование», выражающееся в мобилизации и трансформации системы здравоохранения.

Конечно, у эпидемиологического перехода есть свои предпосылки, к ним относятся и «изменения в структуре организованного социального реагирования в связи с состоянием здоровья». Но, во-первых, отнюдь не только они. А во-вторых, нет никаких оснований считать предпосылки какого-либо процесса его сутью или даже его составной частью.

\footnotetext{
1 Этот термин (transition sanitaire) используется во франкоязычной литературе, так как во французском языке так же, как и в русском, нельзя образовать прилагательное от слова «здоровье». По той же причине принимаем именно этот термин и мы, хотя какие-то нюансы, содержащиеся в английском выражении health transition, при этом утрачиваются.
} 
Скорее, можно сказать, что взгляд Омрана на всю панораму перемен, объединяемых понятием «эпидемиологический переход», был не уже, а шире взгляда его критиков. Он говорит о трех основных группах детерминант, обусловивших переход от эры инфекционных к эре хронических неинфекционных заболеваний: 1) экобиологических; 2) социально-экономических, политических и культурных; 3) медицинских и здравоохраненческих. При этом он совершенно справедливо отмечает, что «снижение смертности в Европе и в большинстве западных стран в течение XIX столетия... определялось влиянием экобиологических и социально-экономических факторов. Влияние медицинских факторов вплоть до XX столетия было, в основном, случайным» (Omran 1971: 520; Омран 1977: 67). Сейчас это общепринятое представление. «В прошлом значительное снижение смертности в XIX в. часто приписывалось прогрессу в медицине. Ныне превалирует точка зрения, что иммунизация и действенные лечебные методы принесли свои плоды лишь в XX в. (разумеется, за исключением оспы)» (Ливи Баччи 2010: 211).

У сторонников «переименования» эпидемиологического перехода оказалось немало последователей в демографической среде. В многотомном демографическом компендиуме в названии соответствующей главы использован термин «Санитарный переход» (во французской версии "Transition sanitaire", в английской - "Health transition") (Meslé, Vallin 2002; 2006). Авторы главы сочли нужным «принять семантический сдвиг, предложенный Julio Frenk et al. (1991)» и «объединить в более широком представлении о санитарном переходе первую (описанную Омраном) фазу роста продолжительности жизни в основном за счет снижения смертности от инфекционных болезней и вторую фазу, определяющуюся снижением смертности от сердечно-сосудистых заболеваний, и оставить открытыми двери для последующих фаз» (Meslé, Vallin 2002: 444; 2006: 250).

Но сам Омран с предложением о «переименовании» эпидемиологического перехода не согласился. Могут происходить какие угодно перемены: социальные, экономические, демографические, медицинские, технологические, экологические - они влияют на здоровье не непосредственно, а через изменение эпидемиологической ситуации, т. е. распространенности тех или иных заболеваний и причин смерти. Именно эта ситуация и предопределяет характерные для популяции состояние здоровья, уровень смертности и продолжительность жизни, и именно в ней совершаются небывалые, невиданные в истории сдвиги - тот самый переход, та самая революция, которые иначе как эпидемиологическими нельзя и назвать. Об этом и говорит Омран, утверждая, что «обозначение всех этих перемен как «санитарного перехода» может внести путаницу. Здоровье - зависимая переменная эпидемиологии, а не наоборот» (Omran 1998: 99; Омран 2019: 178). Последняя фраза ключевая.

\section{ЭПИДЕМИОЛОГИЧЕСКИЙ ПЕРЕХОД И ДЕМОГРАФИЧЕСКИЙ ПЕРЕХОД}

В базовой статье 1971 г. Омран указывал, что стимулом для развития его теории послужило осознание недостатков теории демографического перехода, и, по-видимому, он считал, что концепция эпидемиологического перехода как более всеохватывающая позволяет преодолеть эти недостатки, поскольку «этот вызванный экономическим и социальным 
развитием переход включает в себя изменения характеристик заболеваемости и здоровья (переход в здоровье), изменения в рождаемости и возрастной структуре, ведущие к старению населения (элементы демографического перехода), изменения в образе жизни (переход в образе жизни), изменения структуры здравоохранения (переход в здравоохранении), развитие медицины и технологий (технологический переход) и средовые и экологические изменения (экологический переход)» (Omran 1998: 99; Омран 2019: 178179).

Мне кажется, что, в данном случае, амбиции Омрана чрезмерны. Он - и в этом его главная заслуга - несомненно углубил понимание того, как, начиная, примерно, с XVIII столетия, работал механизм снижения смертности. Можно сказать, что Омран достроил теорию демографического перехода за счет того, что концептуализировал процесс снижения смертности, осознававшийся прежде в основном на уровне описания его результатов.

Можно сказать даже больше. Когда Омран утверждает, что «повышение показателей дожития в младенческом и детском возрастах подрывает комплекс причин социального, экономического и эмоционального порядка, которые побуждают индивидов иметь больше детей, а общество - ратовать за высокую рождаемость» (Omran 1971: 530; Омран 1977: 74), то он демонстрирует теоретическую интуицию, выгодно отличающую его и от А. Ландри, и от Ф. Ноутстайна с его длинным списком социальных и экономических перемен как причин снижения рождаемости, и от многих других солидаризирующихся с Ландри или Ноутстайном авторов, (см. подробнее об этом: Вишневский 2017: 12-16). Ясно высказанное Омраном понимание механизма не только снижения смертности (здесь он первопроходец), но и снижения рождаемости, дает основания отнести его самого к числу классиков теории демографического перехода.

Но когда Омран беспредельно расширяет понимание эпидемиологического перехода, включая в него самые разные, в том числе и отдаленные его последствия, такая «экспансия» оказывается непродуктивной. Она смещает фокус с анализа демографического перехода как ключевого, основополагающего сдвига, который, уже реализовавшись и в снижении смертности, и в снижении рождаемости, действительно порождает бесчисленные и чрезвычайно важные социальные результаты. Внимание переключается на рассмотрение всего спектра многообразных экономических, социальных и прочих изменений, в результате чего их демографическая первооснова уходит в тень и лишний раз недооценивается.

Эпидемиологический переход имеет две ипостаси, каждая из которых исключительно важна, при том, что они имеют совершенно разный смысл.

Во-первых, эпидемиологический переход тождествен небывалому, не имеющему прецедентов в истории, снижению смертности и продлению человеческой жизни. Это и в самом деле огромная революция, значение которой трудно переоценить. Оно огромно и для любого человека, и для тех, чья профессиональная деятельность связана с охраной здоровья и жизни людей, и для всего общества, которое получает гигантские выгоды от неожиданной «рентабельности» становящегося всеобщим долгожительства. При повышении средней продолжительности жизни с 30-35 до 75-80 лет меняется все: экономика, культура, мораль, 
жизненный путь людей. Осознав новые возможности, общество направляет усилия и ресурсы на их реализацию, развивает современные системы здравоохранения, добивается большего или меньшего успеха.

Но во-вторых (по счету, но не по значению), эпидемиологический переход тождествен нарушению извечного демографического баланса, а это - нечто совсем иное, чем продление человеческой жизни. Ответом общества на новую ситуацию становится снижение рождаемости, которое позволяет восстановить нарушенный баланс, этот переход к новому типу демографического баланса и получил название «демографического перехода». К этому термину, в первую очередь, отсылает и термин «эпидемиологический переход». Эпидемиологический переход выступает в качестве триггера демографического перехода, его составной части, но едва ли можно согласиться с его расширительным толкованием, согласно которому эпидемиологический переход «включает в себя» снижение рождаемости, старение населения и другие проявления демографического перехода.

К сожалению, как это можно видеть на примере перетягивания каната в сторону «санитарного перехода», указанная вторая ипостась эпидемиологического перехода и ее фундаментальное значение нередко упускаются из виду или недооцениваются, а сам этот переход воспринимается как нечто, проходящее исключительно по ведомству здравоохранения², что приводит к девальвации концепции Омрана.

\section{ПЕРИОДИЗАЦИЯ ЭПИДЕМИОЛОГИЧЕСКОГО ПЕРЕХОДА}

Поясняя свою идею эпидемиологического перехода как «сдвигов в моделях смертности и заболеваемости» (shifts in mortality and disease patterns), Омран выделяет три последовательных этапа таких сдвигов (эпоха заболеваний и голода; эпоха снижающейся пандемии; эпоха дегенеративных и антропогенных (man-made) 3 заболеваний) (Omran 1971: 516-517; Омран 1977: 64). Первый из этих этапов - это «продолжение тех показателей здоровья, которые характерны для досовременной эпохи» (Там же), «сохранение эпидемиологических моделей прошлого» (Omran 1998: 103; Омран 2019: 183-184). Но в чем тогда отличие этого этапа от остальной «досовременной эпохи»? По существу, Омран включает в состав перехода и предшествующее (всю человеческую историю), и последующее состояния, т. е. то, от чего и к чему совершается переход. Казалось бы, эта странная логика должна была в первую очередь вызвать корректирующую критику: мы же не считаем царское самодержавие и советскую власть этапами революции, приведшей к

\footnotetext{
2 Возможно, сказалось то, что одним из идеологов «санитарного перехода» был Хулио Фрэнк - видный деятель здравоохранения, министр здравоохранения Мексики в первой половине 2000-х годов. «Демографическая» ипостась эпидемиологического перехода» могла его мало интересовать. ${ }^{3}$ В русском переводе выражение «man-made diseases» почему-то передано как «профессиональные заболевания», тогда как Омран относил к ним «например, радиационное заражение, производственные травмы, воздействие химического и биологического оружия, загрязняющих окружающую среду веществ, дорожно-транспортные происшествия и авиакатастрофы, источники канцерогенной опасности в промышленности, в окружающей среде или в пищевых добавках» (Omran 1998: 104; Омран 2019: 185-186).
} 
смене одного другим. Но произошло нечто совсем иное: последователи и критики Омрана стали, соревнуясь между собой, лихорадочно добавлять к бессмысленным этапам Омрана новые.

В эту игру включился и сам Омран. Незадолго до смерти он опубликовал статью под названием «Концепция эпидемиологического перехода: взгляд 30 лет спустя», в которой дал краткий обзор эволюции концепции (Omran 1998; Омран 2019), где, в частности, упомянул авторов (Olshansky, Ault 1986; Rogers, Hackenberg 1987), предлагавших рассматривать четвертый этап перехода. В принципе, он соглашается с этим предложением, хотя его покладистость в данном случае не совсем понятна. Мы видели, что первоначально он обозначил третью стадию как стадию дегенеративных и антропогенных заболеваний, когда ожидаемая продолжительность жизни «достигает небывалого уровня 70 лет и выше» (Omran 1971: table 4; Омран 1977: 83). Ольшанский и От в 1986 г. предложили дополнить схему Омрана четвертым этапом, который они назвали «эпохой отсроченных дегенеративных заболеваний» (the age of delayed degenerative diseases), когда ожидаемая продолжительность жизни увеличится «до восьми десятков лет, а возможно, и больше» (Olshansky, Ault 1986: 386). Даже словесно их четвертый этап ничем не отличается от третьего этапа Омрана: отсроченные дегенеративные заболевания все равно остаются дегенеративными, а ожидаемая продолжительность жизни в 80 лет и больше вполне вписывается в формулировку Омрана «70 лет и выше».

Но теперь и сам Омран говорит о четвертой стадии перехода, которую он характеризует как «эпоху снижения смертности от болезней системы кровообращения, старения, изменения образа жизни, возникновения новых болезней» (Omran 1998: 104; Омран 2019: 186). Мало того, он постулирует пятую стадию, которая наступит в середине XXI века и станет «одним из величайших достижений человечества в области контроля болезней, укрепления здоровья и дальнейшего продления здоровой жизни» (Omran 1998: 115; Омран 2019: 207), и делится своим предположением о том, что «ожидаемая продолжительность жизни продолжит расти, достигнув или превысив 90 лет»» (Там же).

Критикуя первоначальное выделение Омраном трех «эпох», нельзя не отдать ему должное в том, что он при этом крупными мазками разделил всю историю человеческой смертности на три принципиально разных отрезка и тем придал своей периодизации исторический масштаб, который, как мы увидим ниже, был замечен и оценен. Идя же навстречу своим критикам, он отказывается от такого укрупненного видения истории, и его изначально неточная периодизация приобретает совсем причудливый вид: в ней на равных правах присутствуют десятки тысячелетий палеолита, тысячелетия неолита и несколько десятилетий после 1970 г., когда развитые страны, по-видимому, просто вступили в завершающую стадию перехода к новой эпидемиологической модели смертности. Это совершенно естественное развитие событий для феномена, понимаемого как «переход»: он должен иметь начало и конец. 


\section{ДВЕ «ЭПИДЕМИОЛОГИЧЕСКИЕ РЕВОЛЮЦИИ» МИЛТОНА ТЕРРИСА}

Практически одновременно с началом триумфального шествия идеи Омрана об эпидемиологическом переходе и независимо от Омрана сходные с ним идеи высказал другой американский исследователь, известный эпидемиолог, один из основателей американской Национальной ассоциации политики общественного здравоохранения (National Association for Public Health Policy) Милтон Террис. В 1972 г. в журнале, издаваемом этой Ассоциацией, появилась редакционная статья под названием «Эпидемиологическая революция» (The epidemiologic revolution), автором которой был Террис (Terris 1972). Более подробно он развил свои идеи в работе 1976 г. (Terris 1976), за которой последовало множество других публикаций, где он неизменно обращался к этой революции и тем новым вызовам, которые она бросала здравоохранению. Можно только удивляться, что в обильной литературе, посвященной эпидемиологическому переходу, в том числе и американской, имя Терриса обычно даже не упоминается. Впрочем, и Террис никогда не ссылается на статью Омрана, возможно, он даже не знал о ее существовании.

В отличие от Омрана, Террис не пытался вписать современные эпидемиологические перемены в широкую историческую перспективу, его работы имели в большей степени практически цели, были направлены на переориентацию современной системы здравоохранения на решение новых задач. Но, может быть, именно поэтому, он очень четко осознавал 1960-1970-е годы как рубеж, отделявший новые задачи от прежних, что и давало ему основания говорить о двух разных этапах современных эпидемиологических перемен, названных им первой и второй эпидемиологическими революциями. «Мы находимся в начале эпохи... Перед нами стоит большая и трудная задача - ни много ни мало осуществить вторую эпидемиологическую революцию и спасти буквально миллионы мужчин и женщин от предотвратимых болезней, инвалидности и смерти» (Terris 1976: 1159).

Террис перечислил десять главных причин смерти, на борьбу с которыми теперь следовало направить главные усилия здравоохранения: болезни сердца (прежде всего ишемическая болезнь сердца); рак; сосудистые поражения мозга; несчастные случаи; грипп и пневмония; бронхит, эмфизема и другие хронические обструктивные заболевания легких; сахарный диабет; цирроз печени; атеросклероз; родовые травмы, тяжелые роды и другие причины младенческой смертности (Terris 1976: 1156).

Этот список, конечно, более конкретен, чем общее указание Омрана на «дегенеративные и рукотворные заболевания», но в основном он укладывается в это обобщенное определение. Если такие заболевания, как грипп, и не подпадают под него, то это все же не противоречит общему смыслу задач, в решении которых Террис видел смысл «второй эпидемиологической революции». Но важно то, что он рассматривал ее не как сумму частных «революций», а как иุелостный процесс.

Именно в силу такой целостности, позволяющей остаться на более высоком уровне обобщения, используемая Террисом двухчастная схема рассмотрения эпидемиологического перехода, если понимать под ним идущие с XIX века изменения эпидемиологической модели заболеваемости и смертности, кажется мне более 
плодотворной, чем представления сторонников концепции «многофазного» санитарного перехода.

\section{МИФ О КАРДИОВАСКУЛЯРНОЙ РЕВОЛЮЦИИ}

Отказ от целостного взгляда на эпидемиологический переход и связанные с ним издержки ярко проявились в концепции так называемой «кардиоваскулярной революции». Разумеется, ни у кого нет монополии на использование тех или иных терминов или придания им того или иного смысла. Вполне можно говорить о «кардиоваскулярной» революции, так же как, скажем, о «бактериологической» или «санитарно-гигиенической» революциях на предыдущем историческом этапе. Вопрос заключается в уровне обобщения, на который претендует тот или иной термин. Снижение уровня обобщения - это движение от концептуализации к описательности, к эмпиризму, который, конечно, тоже нужен, но как начальная точка исследования, а не как его обладающий эвристическими свойствами результат. А утрата общей перспективы чревата серьезными издержками.

Признав существование «четвертой стадии» эпидемиологического перехода, Омран писал, что «наиболее характерной чертой этого этапа, которая также знаменует его начало [курсив Омрана], является стабилизация, а затем снижение уровней смертности от сердечно-сосудистых заболеваний, которое началось около 1970 г. во многих развитых странах» (Omran 1998: 104; Омран 2019: 186). Тем не менее критики Омрана утверждают, что его концепция «не учитывает того факта, что новая эра прогресса, открывшаяся на рубеже 1970-х годов, основана на серьезном эпидемиологическом изменении, кардиоваскулярной революции, которая отличается от победы над инфекционными болезнями, за которой она следует» (Meslé, Vallin 2002: 444). В английской версии это звучит даже сильнее: «никак не связана с окончанием эры инфекционных заболеваний, хотя и следует непосредственно за ней» (is not linked in any way with the end of the era of infectious diseases, even though it did follow closely) (Meslé, Vallin 2006: 250).

С точки зрения исторической логики, да и логики вообще, это очень странное утверждение, хотя, к сожалению, его нередко можно слышать из уст и других именитых демографов. Например, как писал Дж. Колдуэлл, «то, что произошло при переходе в смертности было победой над инфекционными заболеваниями, а не загадочным замещением инфекций дегенеративными болезнями в качестве причины смерти» (Caldwell 2001: 159). Не менее странной выглядит критика «представления о том, что одни болезни более приемлемы для общества, чем другие. Замещение инфекций несчастными случаями и хроническими заболеваниями часто называют признаком «прогресса». Некоторые доходят до крайности, называя последнее «недугом цивилизации». Фактически, эти проблемы со здоровьем являются результатом неправильного процесса индустриализации, в котором экономическому росту отдавался приоритет перед ростом благосостояния» (Frenk et al. 1989: 31).

На самом деле, ничего загадочного в замещении одних причин заболеваний и смерти другими нет, одни причины действительно «более приемлемы», чем другие, а замещение «менее приемлемых» «более приемлемыми» составляет саму суть эпидемиологического 
перехода. Несомненно и то, что этот переход - одно из ярчайших проявлений человеческого прогресса.

Поскольку все люди смертны, подавление одной причины смерти неизбежно приводит к замещению ее какой-то другой, иначе и не может быть. Стремительное снижение смертности от инфекционных болезней привело к столь же стремительной экспансии смертности от других причин, среди которых важнейшее место принадлежало сердечно-сосудистым заболеваниям. Утверждение, что «кардиоваскулярная революция отличается от победы над инфекционными болезнями», с одной стороны, банально, а с другой - неверно. Если под кардиоваскулярной революцией понимается снижение вероятности смерти от сердечно-сосудистых заболеваний, то их место должны занять какие-то другие причины смерти, как это и было на предыдущем этапе, когда эти заболевания в качестве причины смерти сами вытесняли инфекционные болезни. В этом смысле никакого отличия нет. Другое дело, вопрос о том, на каком этапе своей «исторической карьеры» кардиоваскулярные причины смерти действительно играли революционную роль.

В какой-то момент сердечно-сосудистые заболевания и в самом деле стали главной «болезнью цивилизации», причем, вопреки обывательско-журналистскому дискурсу об этих болезнях как о страшной напасти, это было огромным прогрессом и стало важнейшей составляющей «первой эпидемиологической революции» Терриса или «поздних стадий» эпидемиологического перехода Омрана. При желании именно это можно было бы назвать кардиоваскулярной революцией - и даже с большим основанием, чем то, что называют такой революцией сейчас.

Стандартное описание ситуации, сложившейся накануне так называемой кардиоваскулярной революции, выглядит примерно следующим образом: «В то время как во всех европейских странах зарегистрирован устойчивый рост ожидаемой продолжительности жизни, главным образом в результате ускоренного снижения младенческой смертности и инфекционных заболеваний, этот рост остановился в 1960-х годах, поскольку появились новые эпидемиологические угрозы в виде увеличения смертности от сердечно-сосудистых заболеваний, транспортного травматизма и других причин, связанных с рискованным поведением. Согласно теории эпидемиологического перехода, эти неблагоприятные явления должны были сдерживать дальнейший прогресс в продолжительности жизни» (Fihel, Pechholdova 2017: 652).

Это описание не имеет ничего общего ни с действительностью, ни с теорией эпидемиологического перехода, по крайней мере, в той части, где речь идет о сердечнососудистых заболеваниях, которые совершенно бессмысленно поставлены рядом с транспортным травматизмом. «Эпидемиологические угрозы в виде увеличения смертности от сердечно-сосудистых заболеваний» появились на 100 лет раньше, и они вовсе не были угрозами, потому что такое увеличение смертности одновременно означало и повышение среднего возраста смерти, т. е. то, к чему и следовало стремиться. Более того, выигрыш в годах жизни в этом случае был наибольшим из всех возможных, потому что средний возраст смерти от любого другого класса причин смерти был ниже, чем от болезней системы кровообращения (рисунок 1). 


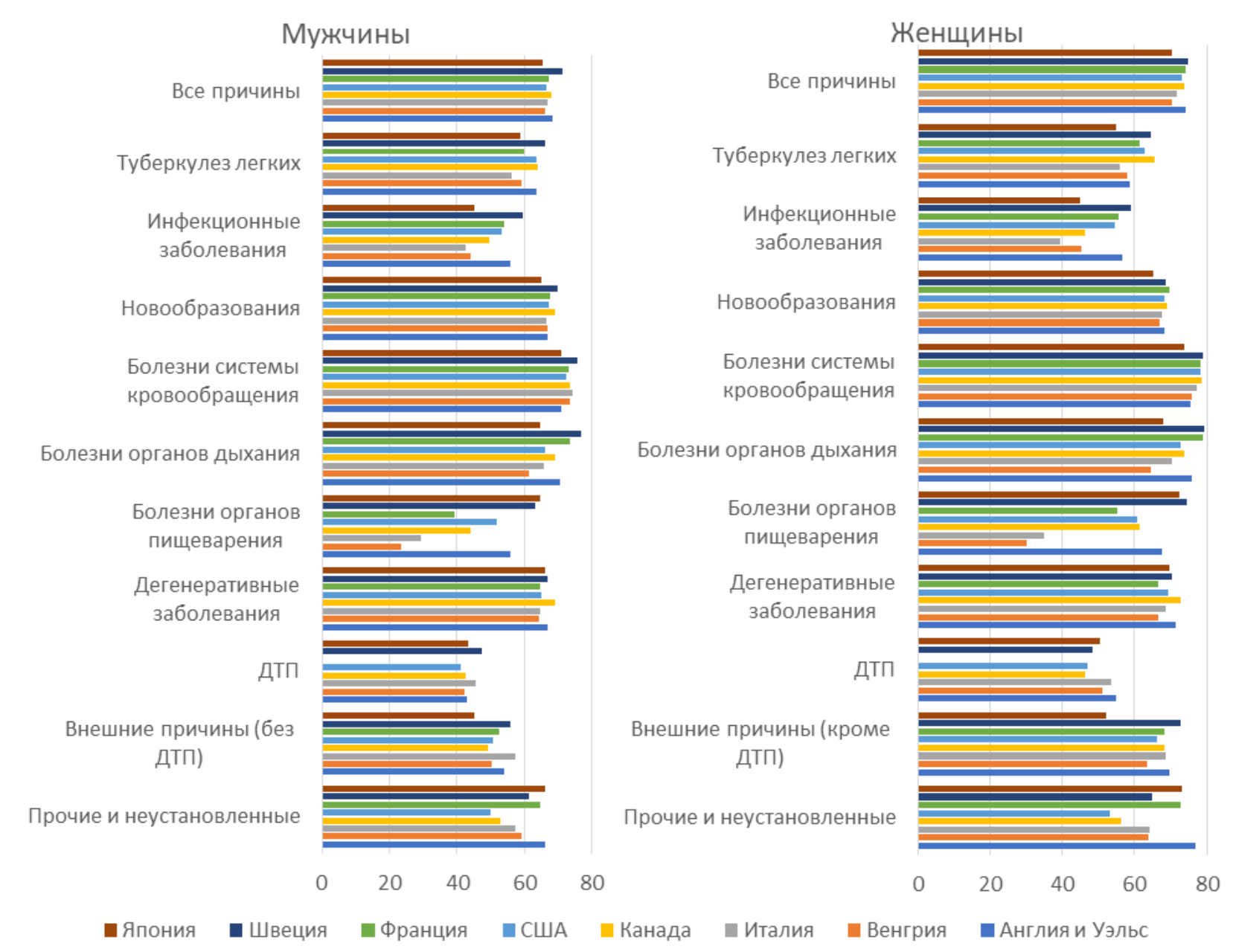

Рисунок 1. Средний возраст смерти от разных причин в некоторых странах в 1960 году, лет

Источник: (Preston, Keyfitz, Schoen 1972).

То, что происходило на самом деле, можно хорошо видеть на примере Англии и Уэльса, так как в этом случае имеются достаточно длинные ряды данных. Стремительный рост вероятности умереть от болезней системы кровообращения (рисунок 2) в сочетании со столь же быстрым ростом среднего возраста смерти от этих болезней (рисунок 3) на протяжении 100 лет был главным локомотивом роста продолжительности жизни. Среднестатистический человек, умерший от этой причины, мог считаться вытянувшим счастливый билет, потому что любая другая причина подвела бы его к краю могилы раньше.

Что означал случившийся в 1970-е годы поворот, когда шансы для новорожденного умереть от причин, относящихся к классу болезней системы кровообращения, стали снижаться? Именно это снижение и называют «кардиоваскулярной революцией». В чем же ее смысл? Когда на предыдущем этапе шансы умереть от этих причин росли, одновременно росли и шансы умереть в более позднем возрасте. А что происходит сейчас? 


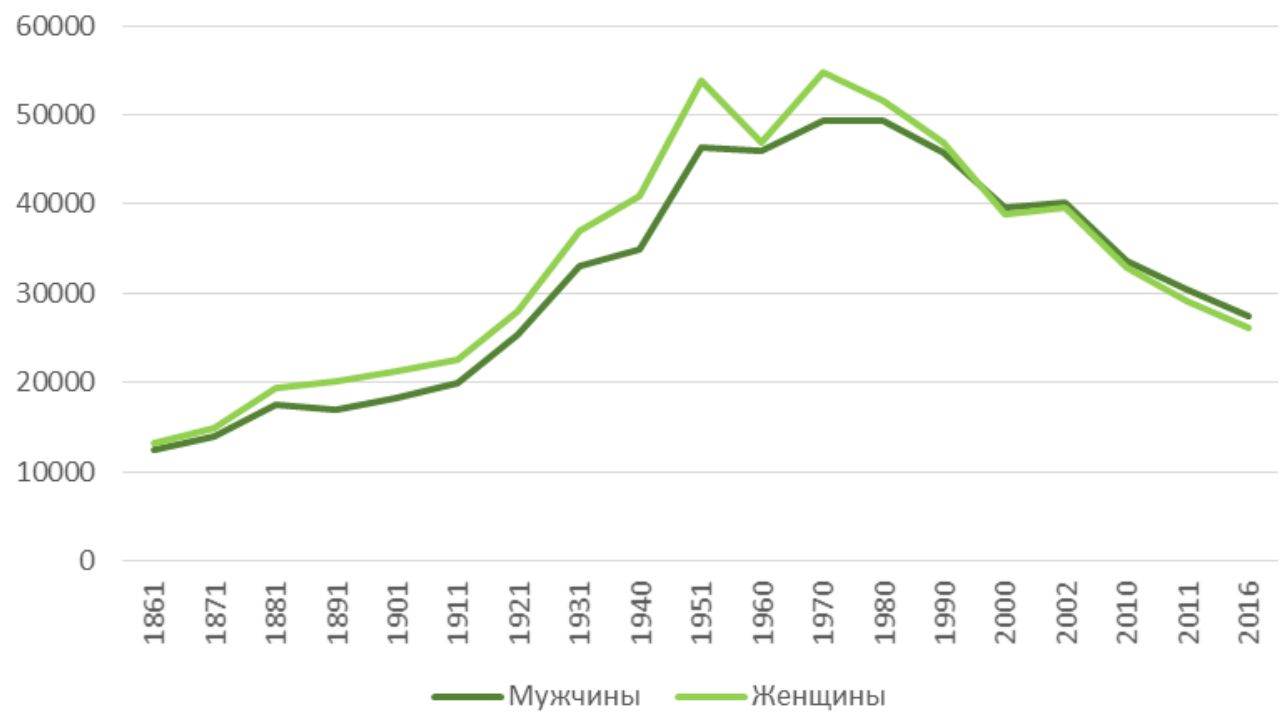

Рисунок 2. Вероятность для новорожденного умереть от болезней системы кровообращения, Англия и Уэльс, 1861-2016, на 100 тыс. родившихся

Источники: (Preston, Keyfitz, Schoen 1972; Human Cause-of-Death Database; WHO Mortality Database).

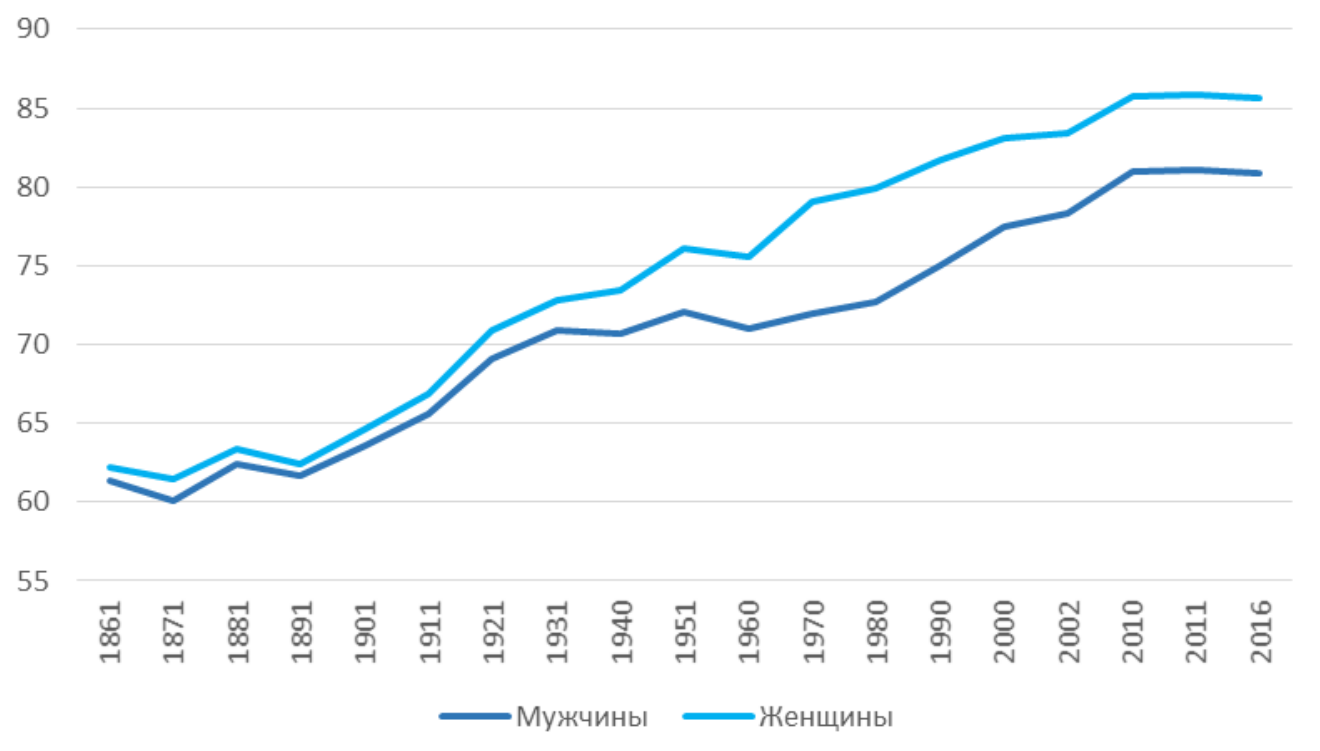

Рисунок 3. Средний возраст смерти от болезней системы кровообращения, Англия и Уэльс, 1861-2016, лет

Источники: (Preston, Keyfitz, Schoen 1972; Human Cause-of-Death Database; WHO Mortality Database).

Не означает ли снижение роли болезней системы кровообращения как причины смерти, что у них появились более удачливые конкуренты с еще более высоким средним возрастом смерти и воспроизводится ситуация вековой давности, когда сердечнососудистые заболевания демонстрировали свои конкурентные преимущества перед инфекционными болезнями, часто обрывавшими жизнь человека в самом ее начале? 


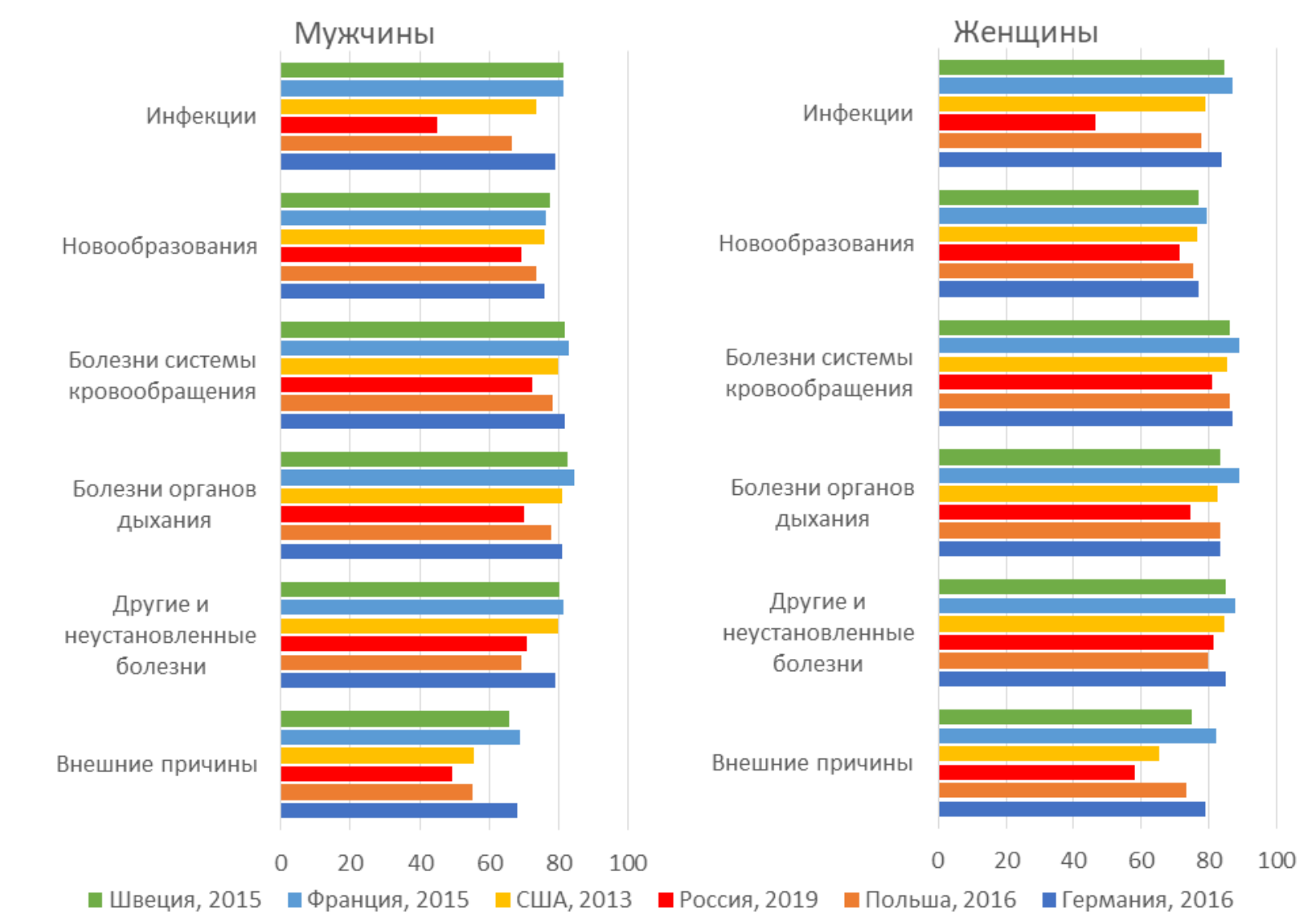

Рисунок 4. Средний возраст смерти от разных причин в некоторых странах, лет. Последние имеющиеся данные

Источники: (Preston, Keyfitz, Schoen 1972; Huтаn Cause-of-Death Database; WHO Mortality Database).

Сравнение рисунка 1 с рисунком 4 показывает, что принципиальных изменений в соотношении средних возрастов смерти от разных причин за минувшие полвека не произошло. Правда, у болезней системы кровообращения появился конкурент с несколько более высоким средним возрастом смерти - болезни органов дыхания. Это, по-видимому, следствие того, что, уже достигнув очень преклонного возраста, люди становятся более уязвимыми для простудных заболеваний, пневмоний, от которых, напротив, перестали умирать дети, - отсюда и повышение среднего возраста смерти от этих причин. В остальном же сердечно-сосудистые заболевания по-прежнему остаются наиболее «выгодной» причиной смерти, и в этом смысле их преимущество продолжает увеличиваться: средний возраст смерти от них продолжает расти, по крайней мере, так было до последнего времени (рисунок 3). В этом смысле никакой революции не произошло, сохраняются тенденции, сложившиеся еще в середине XIX века. Снижение же вероятности смерти от болезней системы кровообращения, приветствуемое как революция, на деле факт, скорее негативный, хотя, видимо, и неизбежный.

Реальная картина изменений в процессе продолжающегося эпидемиологического перехода определяется сложным взаимодействием причин смерти между собой и не непосредственно, а через их связь с возрастом. Человек в своем движении по жизни напоминает сказочного Колобка: он и от дедушки ушел, и от бабушки ушел... А старую лису не перехитришь. 
Если человек доживает до преклонных лет со здоровым сердцем, но умирает от пневмонии, об этом можно сожалеть: если бы не пневмония, он бы мог прожить еще какоето время. Тем не менее, если ориентироваться на приведенные выше современные показатели для Англии и Уэльса, в среднестатистическом смысле он оказывается в лучшем положении, чем большинство людей из его когорты, которые умерли от сердечнососудистого заболевания более молодыми, не дожив до своей пневмонии.

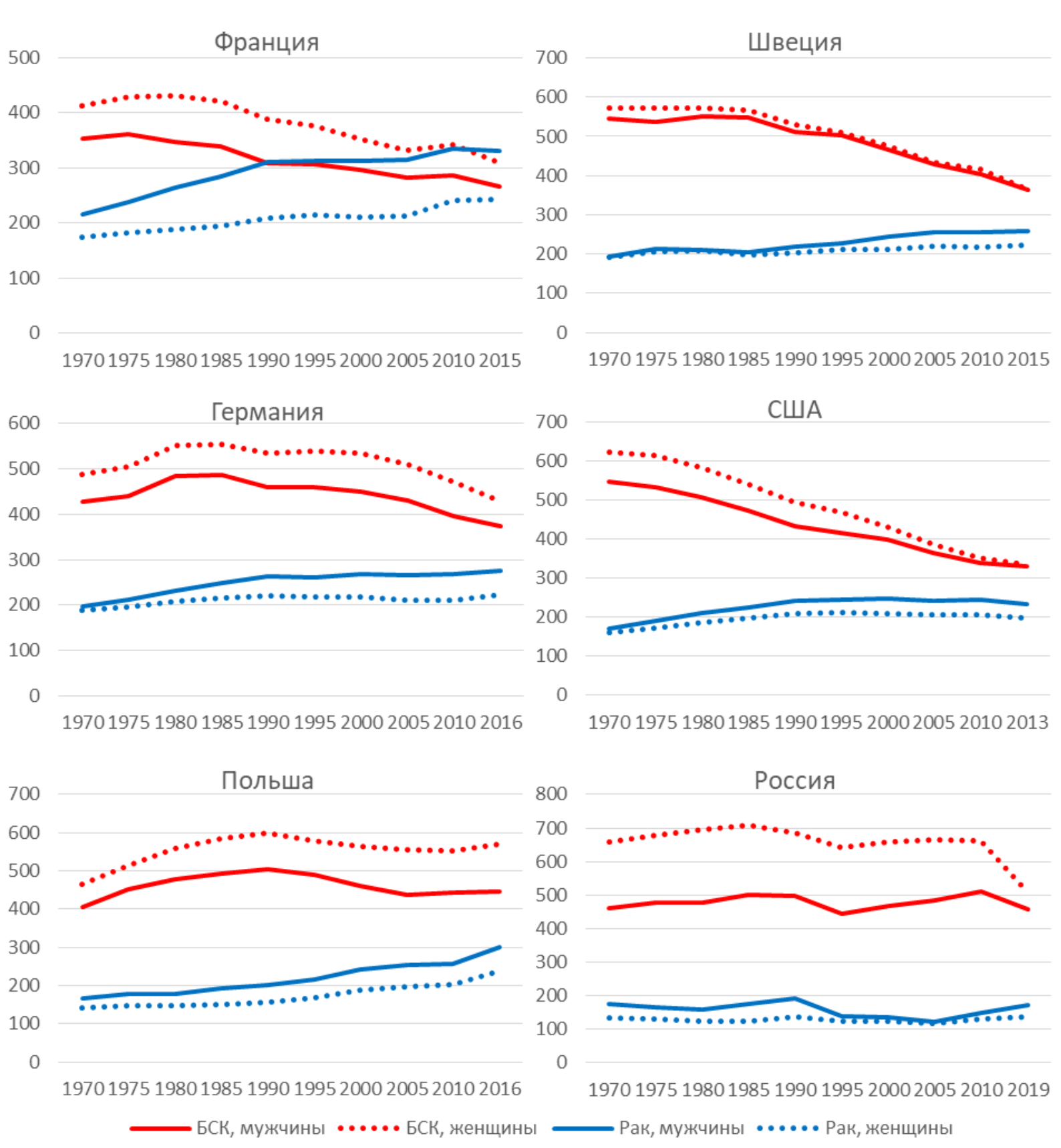

Рисунок 5. Вероятность для новорожденного умереть от болезней системы кровообращения и от рака с 1970 г. в некоторых странах, на 1000

Источники: (Human Cause-of-Death Database; WHO Mortality Database).

Но если мы в нашем рассуждении заменим пневмонию раком, то вывод будет иным. Человек, доживший до своего рака и умерший от него, проигрывает по сравнению с той 
частью своей когорты, которая умирает от болезней системы кровообращения. Но это происходит с ним именно потому, что он не умер от таких болезней ранее. Повышение среднего возраста смерти от болезней системы кровообращения сохраняет часть когорты для рака, и это именно то, что в той или иной степени происходит сейчас во всех развитых странах: вероятность для новорожденного умереть от болезней системы кровообращения снижается, а вероятность умереть от новообразований растет (рисунок 5).

Но при этом средний возраст смерти увеличивается и для той, и для другой группы причин смерти (к сожалению, это лишь отчасти справедливо для России) - см. таблицу.

Таблица. Прирост среднего возраста смерти от болезней системы кровообращения (БСК) и новообразований с 1970 г. в 6 странах, лет

\begin{tabular}{l|c|c|c|c}
\hline & \multicolumn{2}{|c|}{ Мужчины } & \multicolumn{2}{c}{ Женщины } \\
\cline { 2 - 5 } & Новообразования & БСК & Новообразования & БСК \\
\hline Франция, 1970-2015 & 8,3 & 8,9 & 7,7 & 9,1 \\
Швеция, 1970-2015 & 5,7 & 5,7 & 5,2 & 5,1 \\
Германия, 1970-2016 & 7,6 & 8,9 & 7,4 & 8,5 \\
США, 1970-2013 & 8,2 & 7,3 & 7,0 & 5,2 \\
Польша, 1970-2016 & 3,5 & 2,9 & 4,3 & 5,5 \\
Россия, 1970-2019 & 5,3 & 0,0 & 5,4 & 2,4 \\
\hline
\end{tabular}

Источники: (Human Cause-of-Death Database; WHO Mortality Database).

Если учесть, что болезни системы кровообращения и новообразования обусловливают 50-70\% всех смертей, их взаимодействие и определяет в первую очередь эволюцию эпидемиологической модели смертности на нынешнем этапе эпидемиологического перехода. А это взаимодействие складывается так, что сердечнососудистые заболевания как причина смерти проигрывают онкологическим: все больше людей из каждой условной когорты имеют шанс умереть от рака и раньше, тогда как шансы умереть от заболевания сердца или сосудов, но позже, падают. Можно ли это назвать революцией?

\section{ГРАФИЧЕСКОЕ ПРЕДСТАВЛЕНИЕ ЭПИДЕМИОЛОГИЧЕСКОГО ПЕРЕХОДА}

Для того чтобы лучше понять взаимоувязанную динамику смертности от разных причин смерти в процессе эпидемиологического перехода, надо рассматривать сопряженные изменения распространенности тех или иных причин, с одной стороны, и возраста смерти от каждой из них - с другой, причем не отдельных причин, а всей их совокупности. В качестве удобного инструмента такого анализа нами еще в 1980-е годы было предложено графическое представление таких сопряженных изменений, дающее наглядную картину одновременных сдвигов значений обоих названных параметров: вероятности смерти от каждой из причин и среднего возраста смерти от нее.

Каждый график представляет собой набор прямоугольников, количество которых соответствует числу рассматриваемых укрупненных причин, ширина - значениям вероятностей для новорожденного умереть от причины $i\left(P_{i}\right),\left(i=1,2,3 \ldots n ; \sum P_{i}=1\right)$, а высота - значениям $\overline{\mathrm{X}}_{i}$. Соответственно площадь такого прямоугольника - ожидаемое число человеко-лет, которое проживут люди из рассматриваемой исходной совокупности 
родившихся, умирающие от данной причины смерти. Сумма же площадей всех прямоугольников соответствует числу человеко-лет, которое проживут люди, умершие от всех причин, или, что то же самое, вся совокупность родившихся. Это величина эквивалентна значению $T(0)$ таблицы смертности. Будучи разделенной на корень таблицы, она дает $е(0)$ - ожидаемую продолжительность жизни для всей совокупности родившихся. Так как в данном случае мы рассматриваем распределение не абсолютных чисел, а вероятностей, которые в сумме дают единицу $\left(\sum P_{i}=1\right)$, то и делить надо на 1. Соответственно

$$
e(0)=\sum P_{i} \bar{x}_{i}
$$

Чем больше совокупная площадь всех прямоугольников, тем выше продолжительность жизни.

Каждый отдельный график можно рассматривать как актуальную эпидемиологическую модель смертности для отдельной страны или отдельного региона, но сравнительный анализ, позволяющий выявить изменения во времени или пространственные различия, указывает на наличие типичных моделей и на эволюцию от одних типов к другим. Резкие и сходные различия между типами, возникающие в ходе такой эволюции на ее современном этапе, и дают основания говорить о становлении нового типа эпидемиологической модели смертности, в чем и заключается суть эпидемиологического перехода.

На рисунке 6 представлено распределение времени жизни поколений мужчин и женщин в условиях смертности в Англии и Уэльсе в 1861, 1960 и 2016 г.

Огромный рост продолжительности жизни поколений немногим больше, чем за полтора столетия с 1861 по 2016 г. очевиден. Ожидаемая продолжительность жизни мужчин и женщин выросла на 38,9 и на 40 лет - соответственно в 2 и в 1,9 раза. $71 \%$ прироста продолжительности жизни у мужчин и 77,5\% у женщин достигнуты за первые 100 лет с 1861 по 1960 г., это плоды «первой эпидемиологической революции» Терриса. Вклад последних 50 лет «второй эпидемиологической революции» скромнее, правда, и период вдвое более короткий. 

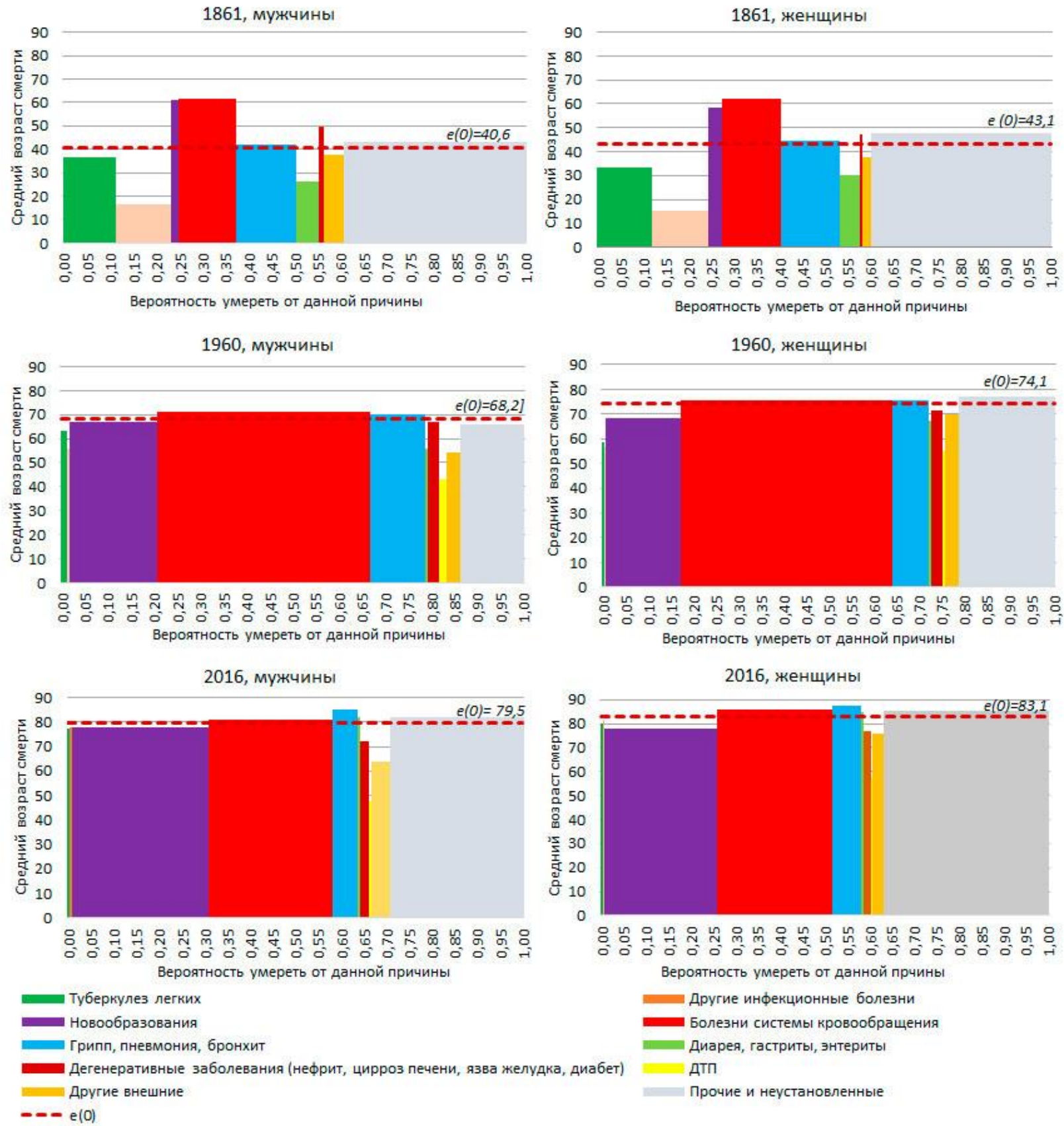

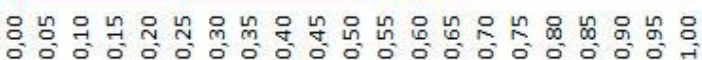
Вероятность умереть от данной прчины

Другие инфекционные болезни

Болезни системы кровообращения

Диарея, гастриты, энтериты

дтп

Прочие и неустановленные

Рисунок 6. Время жизни поколений мужчин и женщин и его распределение по числу прожитых лет в зависимости от причины смерти в условиях смертности в Англии и Уэльсе в 1861, 1960 и 2016 гг., человеко-лет (площади прямоугольников)

Источники: (Preston, Keyfitz, Schoen 1972; Human Cause-of-Death Database).

Но важно то, как изменилась эпидемиологическая картина смертности. При переходе от модели смертности 1861 г. к модели 1960 г. резко сократилась смертность от туберкулеза, других инфекционных, а также желудочных заболеваний, т. е. причин, ассоциирующихся с наиболее низким возрастом смерти. Их место заняли совсем другие причины, причем при переходе от одной модели к другой, в среднем, больше всех выиграли те, кому повезло умереть от болезней системы кровообращения, а среди женщин также те, кто умер от гриппа, пневмонии или бронхита, - все эти люди, опять-таки в среднем, 
прожили дольше всех своих условных сверстников. Впрочем, у женщин даже несколько больше выиграли умершие от прочих и неустановленных причин.

К 1960 г. причины с ярко выраженным низким возрастом смерти в основном утратили свое значение, теперь главным резервом роста продолжительности жизни стало увеличение среднего возраста смерти от оставшихся причин. Это и происходит сейчас во всех странах в результате более или менее скоординированных действий систем здравоохранения и других государственных и общественных структур, ответственных за сохранение здоровья и жизни граждан. Относительно низкий средний возраст смерти от ключевых ее причин в России (рисунок 4) - несомненный признак ее отставания.

\section{ЗАВЕРШЕНИЕ ЭПИДЕМИОЛОГИЧЕСКОГО ПЕРЕХОДА}

Графики, подобные представленным на рисунке 6, но относящиеся к Англии и Уэльсу в 1861, 1911 и 1964 г., были впервые использованы в статье 1986 г. (Андреев, Вишневский, Шабуров 1986). Представление об эпидемиологическом переходе в этой статье отсутствовало, хотя и говорилось о «новом историческом типе смертности» в развитых странах, который связывался со «скачкообразным ростом контроля общества над экзогенными факторами смертности в результате перехода от аграрной к индустриальной экономике» (Андреев, Вишневский, Шабуров 1986: 114). Но несколько лет спустя двухмерные графики структуры смертности по причинам смерти уже рассматривались именно как инструмент анализа эпидемиологического перехода (Вишневский, Школьников, Васин 1991; Vishnevsky, Shkolnikov, Vassin 1991). «Эпидемиологический переход» авторы предпочли более нейтральному «переходу к новому типу смертности», потому что термин Омрана указывал на differentia specifica этого перехода, на суть перемен.

На основе анализа структуры причин смерти в 31 развитой стране в 1974-1976 гг. авторы упомянутой выше публикации 1986 г. пришли к выводу, что «период радикальной перестройки структуры причин смерти в основном остался позади» и, в отличие от предыдущего периода, четкой связи между средней продолжительностью жизни и вероятностью умереть от различных причин больше нет (Андреев, Вишневский, Шабуров 1986: 122). Там же отмечалось, что к сходному выводу пришли и изучавшие проблемы продолжительности жизни биологи, которые сформулировали - пусть и в виде гипотезы и исходя из других оснований - положение о том, что «ликвидация отдельных причин смерти не может изменить величину возрастного приращения интенсивности смертности» (Гаврилов 1984: 908-909). Развивавшее эту мысль и претендовавшее на универсальность утверждение о том, что «причины смерти представляют собой лишнюю сущность, без которой вполне можно обойтись при прогнозировании смертности людей» (Гаврилов, Гаврилова 1986: 82), было явно несостоятельным применительно к периоду эпидемиологического перехода. Но факт растущей независимости ожидаемой продолжительности жизни от изменений в соотношении причин смерти, что совпадает с выводом Гавриловых, может интерпретироваться и как свидетельство об окончании эпидемиологического перехода. 
Обычно - и это одна из самых удивительных черт научного дискурса об эпидемиологическом переходе - при постоянном ожидании следующих стадий, которые принесут новые успехи в борьбе с болезнями и смертью и повышении продолжительности жизни (впрочем, иногда говорят и о новых угрозах), вопрос о завершении перехода даже не ставится. Между тем, коль скоро речь изначально идет о переходе, т. е. о процессе, который по самой своей сути должен быть локализован во времени и иметь начало и конец, он заведомо не может быть бесконечным, как не может быть бесконечным мост, соединяющий один берег реки с другим.

В чем может выразиться завершение эпидемиологического перехода? В какой-то мере ответ на этот вопрос подсказывает рисунок 6, на котором видно исчезновение принципиальных различий в возрасте смерти от различных причин. Коль скоро это происходит, изменение эпидемиологической картины, продолжая оставаться очень важным, с точки зрения эпидемиолога, врача или организатора здравоохранения, перестает интересовать демографа, потому что перестает быть частью демографического перехода. Снижение смертности и рост продолжительности жизни могут продолжаться и после этого, но уже в «эволюционном», а не в «революционном», как во время перехода, режиме. Они будут происходить уже «на другом берегу реки», успехи будут намного более скромными, снижение смертности сместится к старшим возрастам и практически не будет влиять на демографический баланс.

\section{«ПЕРВЫЙ ЭПИДЕМИОЛОГИЧЕСКИЙ ПЕРЕХОД»?}

Прежде чем двинуться дальше, заметим, что смешение уровней обобщения характерно для интерпретации не только эпидемиологического перехода, о чем говорилось выше, но и демографического перехода в целом, включающего в себя эпидемиологический переход как одну из главных составных частей.

Вызванный эпидемиологическим переходом огромный, никогда не наблюдавшийся ранее сдвиг в балансе смертности и рождаемости, необратимо изменивший условия воспроизводства человеческих популяций, и ответное, необходимое для восстановления нарушенного демографического равновесия снижение рождаемости, и составляют суть единого исторического процесса, получившего название «демографический переход» («демографическая революция»).

Демографический переход означал невиданные изменения в самом фундаменте важнейшего, основополагающего социально-биологического процесса, и они не могли не привести к радикальным переменам на всех этажах стоящего на этом фундаменте здания. Такие перемены действительно произошли и продолжают происходить, они очень важны для жизни обществ, которые они затрагивают, но все же речь идет не о самостоятельных переменах, а лишь о следствиях основного, фундаментального сдвига - перехода к новому демографическому балансу. После того, как этот переход начался и был осознан, все его следствия были предсказуемы - в отличие от самой смены баланса, какой человеческая история не знала и люди даже в XVIII веке не могли и предположить. 
Между тем уже сложилась традиция рассматривать эти следствия как рядоположенные, равнозначные основному сдвигу, дробить его на отдельные «революции» или «переходы» - «первый», «второй», «третий» и т. д. (Van de Kaa 1987; Coleman 2004; Eggleston, Fuchs 2012). Создается впечатление, что каждый уважающий себя демограф стремится обзавестись собственным переходом, но в итоге мы видим лишь все большее смещение к описательности в ущерб концептуализации.

Если, как это обычно делается, вести родословную теории демографического перехода (демографической революции) от А. Ландри, то нельзя не видеть, что хотя Ландри, в отличие от Омрана, концентрировал внимание на изменениях не смертности, а рождаемости, он так же, как и Омран, выделял три этапа этих изменений, которые он называл «демографическими режимами» (Landry 2019: 95). В историческом прошлом повсеместно существовал «примитивный» режим, не знавший сознательного ограничения рождаемости. Затем ему на смену пришел «промежуточный» режим, продержавшийся во Франции до конца XVIII века, а в других европейских странах до конца XIX века и затем уступивший место «современному» демографическому режиму. Вся демографическая история сводится, таким образом, к двум основным этапам, разделенным третьим промежуточным и непродолжительным.

По сути, на таких же позициях стояли и американские демографы, развивавшие теорию демографического перехода в 1940-е годы. Вся демографическая история представлялась им похожей «на длинный тонкий пороховой фитиль, который горит медленно и сбивчиво, пока он, наконец, не достигнет заряда, и тогда происходит взрыв... Первый реальный всплеск роста мирового населения пришел с последним этапом культурного прогресса - промышленной революцией» (Davis 1945: 1).

В этом же русле плыл и Омран, когда он всю прошлую историю характеризовал как «досовременную эпоху», на протяжении которой «основными детерминантами смертности являются мальтузианские «объективные сдерживающие факторы», а именно эпидемии, голод и войны» (Omran 1971: 517; Омран 1977: 64). Но к моменту появления его статьи в 1971 г. подобные представления о демографической однотипности «досовременной эпохи» и соответственно о монотонном росте населения Земли в прошлом были поставлены под сомнение.

В 1960 г. журнал Scientific American опубликовал статью Эдварда Диви «The Human Population» (Deevey 1960), получившую широкую известность. В этой статье утверждалось, что на протяжении человеческой истории число людей на Земле увеличивалось не монотонно, а скачками, каждый из которых был ответом на революцию в культуре. Согласно Диви, таких революций (и, соответственно, таких скачков) за всю историю было три. Первая произошла в раннем палеолите, когда человек научился создавать и использовать орудия; вторая - в эпоху неолита, это так называемая «неолитическая революция», ознаменовавшая переход от присваивающей к производящей, аграрной экономике; третья - порождение современной научно-промышленной революции. Каждая такая революция расширяла доступную человеку экологическую нишу, он заполнял ее, после чего демографический рост прекращался и устанавливалось относительное равновесие, не исключавшее постоянных колебаний численности 
населения. Так было, во всяком случае, с двумя первыми революциями. Сейчас сформулированное Диви представление о трех демографических революциях верхнепалеолитической (в отличие от Диви, который относил ее к нижнему палеолиту), неолитической и современной - получило достаточно широкое распространение (см., напр., (Birabin 2006: 16)), однако осмысление сходства и различий этих всемирно-исторических демографических переворотов, по-видимому, еще потребует немалого времени, в том числе и у тех, кто размышляет об эпидемиологическом переходе.

В 1998 г. в американском ежегоднике «Annual Review of Anthropology» была опубликована статья группы авторов под названием «Возникновение и возвращение инфекционных болезней: Третий эпидемиологический переход» (Barrett et al. 1998). Авторы статьи отталкивались от концепции Омрана, ссылались на нее, но развивали представление о том, что выделенный Омраном эпидемиологический переход - не единственный в человеческой истории. При этом они, по крайней мере, отчасти, следовали схеме, сложившейся к этому времени при анализе истории демографических переходов.

Первый эпидемиологический переход Баррет и соавторы относят к эпохе неолитической демографической революции («второй» в системе отсчета Диви), сам факт которой был признан не сразу, несмотря, казалось бы, на его почти полную очевидность. Как с уверенностью писали по этому поводу в 1970 г. венгерские исследователи Ачади и Немешкери, новая хозяйственная система не просто послужила базисом для умножения человечества, она ускорила процесс, который в силу его поразительного сходства с демографической революцией нашего времени может быть назван «демографической революцией эпохи неолита» (Acsadi, Nemeskéri 1970: 196). Однако этот тезис еще долго вызывал сомнения ${ }^{4}$. Так, признавая существенные изменения демографической ситуации во многих районах мира и несомненное ускорение роста населения в неолите, советские специалисты по истории первобытного общества не соглашались с тем, что «некоторые авторы трактуют эти изменения как «первую демографическую революцию» и связывают их с переходом к производящему хозяйству, что, строго говоря, неточно», а «механизмы и масштабы этой «демографической революции» остаются весьма неопределенными» (Шнирельман 1986: 444).

Сейчас сам факт демографической революции эпохи неолита, кажется, не вызывает сомнений, но споры по поводу ее механизмов ведутся долгие годы. И возможно, главной причиной бесконечности этих споров служит то, что в них преобладает стремление увидеть смысл происходивших тогда перемен через призму опыта современного демографического перехода.

Его триггером действительно стал эпидемиологический переход, стремительная смена эпидемиологической модели смертности, что и привело, в конечном счете,

\footnotetext{
${ }^{4}$ У меня сохранилось письмо моего чешского коллеги и друга Зденека Павлика, в то время главного «промоутора» теории демографической революции в «социалистическом лагере», которое он прислал после выхода моей статьи в журнале «Вопросы философии», где, в частности, говорилось и о неолитической демографической революции [Вишневский 1973]. Он одобрительно отозвался о статье, но с оговоркой: «Я не думаю,- писал он, - что в самом деле существуют две демографические революции, которые имеют то же самое значение, но во всем остальном наши взгляды не отличаются».
} 
к радикальному изменению условий демографического равновесия, снижению смертности, обусловленному им снижению рождаемости и всему, что за этим последовало. Но ни из чего не следует, что механизмы предыдущих демографических революций (переходов) были такими же.

Мне уже приходилось писать - со ссылкой на (McEvedy, Jones 1978: 14-15) - о том, что верхнепалеолитическая («первая», по Диви) демографическая революция произошла не потому, что снизилась смертность (Вишневский 2018). Как бы ни были велики достижения палеолитических собирателей и охотников, динамика численности палеолитических популяций Homo sapiens, как и их предшественников в дикой природе, по-прежнему зависела от их плотности. Численность первобытных общин не выросла, а смертность австралийских аборигенов к моменту первых контактов с европейцами в конце XVIII века мало отличалась от смертности кроманьонцев. Прорыв заключался в другом: развитые нашими древнейшими предками технологии и формы социальной организации позволили им безгранично расширить ойкумену, что и сделало возможным рост мирового населения без роста плотности популяций. И можно предположить, что именно освоение все новых и новых пространств в разных природно-климатических зонах планеты было одним из главных мотиваторов технологических, культурных и социальных инноваций, составлявших суть верхнепалеолитической революции, так что «первоначально именно демографические факторы были причиной, а изменение технологии - следствием» (Вишняцкий 2000: 265). В демографических же терминах ускорение роста населения в палеолите имело миграционную природу.

С демографической революцией эпохи неолита («второй», по Диви), связанной с переходом от присваивающей к производящей экономике, дело обстоит иначе. Производящая аграрная экономика впервые ослабила зависимость динамики человеческих популяций от плотности и сделала возможными не только новое ускорение роста численности населения, но и появление огромных скоплений людей, подобных тому, какое возникло, например, несколько тысячелетий назад в долине Нила. Разумеется, это не могло произойти без изменения демографического баланса, соотношения рождаемости и смертности.

Демографический баланс может измениться либо за счет повышения рождаемости, либо за счет снижения смертности, либо за счет и того, и другого. Вопрос о том, что именно произошло в эпоху неолитической революции, вызывает бесконечные споры. Уже не одно десятилетие существует и обсуждается, в частности, точка зрения, согласно которой одним из следствий этой революции стало повышение (а не снижение) смертности, так называемый «неолитический кризис смертности»- см., напр., (Caldwell, Caldwell 2003). Но даже если стать на противоположную точку зрения и признать преобладание позитивных изменений смертности над негативными, дает ли это основания говорить о «неолитическом эпидемиологическом переходе»?

Становление производящей экономики существенно раздвинуло экономические пределы роста населения, но они не исчезли. Судя по всему, не были полностью преодолены и эколого-биологические барьеры, ограничивавшие возможности концентрации людей и их хозяйственной деятельности. Соответственно не перестали 
действовать и естественные механизмы контроля динамики численности популяций. Они лишь приобрели новые, кризисные формы, запечатленные в образе библейского всадника Апокалипсиса: «конь бледный, и на нем всадник, которому имя «смерть»; и ад следовал за ним; и дана ему власть над четвертою частью земли - умерщвлять мечом и голодом, и мором и зверями земными» (Откр. 6: 7-8).

Это и были перечисленные Омраном «сдерживающие факторы» - эпидемии, голод и войны, - которые он, со ссылкой на Мальтуса, приписывает всей «досовременной» истории (Omran 1971; Омран 1977: 64). Но, скорее всего, они существовали не всегда, а появились в результате неолитического рывка и давали о себе знать по мере того, как возможности расширившейся экологической ниши исчерпывались и численность населения приближалась к новой опасной черте. В палеолите же, т. е. на самом продолжительном отрезке человеческой истории, когда смертность, конечно, была очень высокой, но плотность популяций низкой, эти факторы едва ли играли столь же важную демографическую роль.

С появлением производящей экономики и оседлости эпидемиологическая картина, вероятно, изменилась и усложнилась, и для эпидемиолога эти изменения важны, для него они и в самом деле могут означать революцию. Но это революция не того масштаба, какой присущ современной эпидемиологической революции Омрана (предпочитавшего слово «переход»): ее смысл заключается в переходе от неконтролируемой $к$ контролируемой эпидемиологической картине человеческого бытия. Такого перехода в истории человечества еще не было. Соответственно история не знала и подобных радикальных сдвигов в уровне смертности. Даже если продолжительность жизни средневекового европейца или русского крестьянина конца XIX века и была несколько выше продолжительности жизни первобытного человека, то совсем ненамного, различия были не принципиальными. Существенный отрыв от уровня всех прошлых эпох впервые обозначился в некоторых европейских странах не раньше первой половины XVIII века, когда они вступили в «период снижающейся пандемии» Омрана, т. е. когда там начался собственно эпидемиологический переход и красный пунктир на рисунке 7, относящийся, правда, уже к середине XIX века, бесповоротно отделил современную эпоху от всех предыдущих.

Поэтому если есть основания говорить о демографическом переходе эпохи неолита, имевшем экономическую природу, то для утверждений о неолитическом эпидемиологическом переходе оснований нет. Скорее всего, современный эпидемиологический переход - первый и пока единственный, который знала история человечества. 


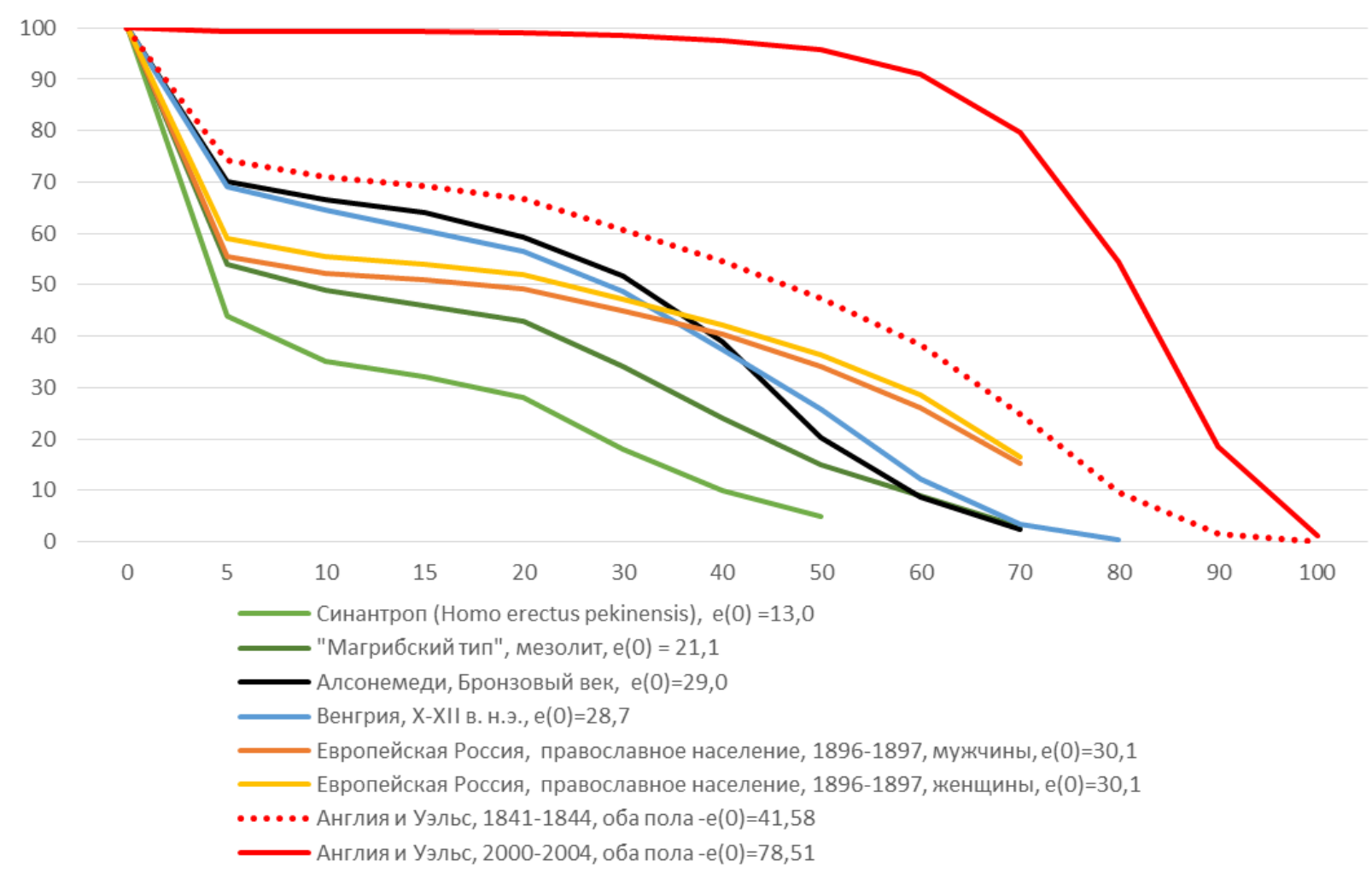

Рисунок 7. Кривые дожития $l_{x}$ в разные исторические эпохи

Источники: (Acsádi, Nemeskéri 1970: 172, 266-267,282-283, 130-309; Паевский 1970: 290; Preston, Keyfitz, Schoen 1972).

\section{«ТРЕТИЙ ЭПИДЕМИОЛОГИЧЕСКИЙ ПЕРЕХОД»?}

В упоминавшейся статье Баррета и соавторов (Barrett et al. 1998) обращение к концепции предполагаемого ими первого эпидемиологического перехода увязано с выстраиванием исторической цепочки, в которой у нынешнего эпидемиологического перехода имеется не только предшествующее, но и последующее звено. Ему и присваивается название «третьего эпидемиологического перехода».

Я отрицаю существование эпидемиологических революций в прошлом, значит ли это, что я отрицаю возможность их появления в будущем? Разумеется, нет, у меня для этого нет надежных оснований. Тем не менее, поскольку мысль о возможности нового эпидемиологического перехода была высказана и получила определенную поддержку в литературе, хотелось бы точнее понять, о чем, собственно, идет речь.

Статья Баррета и соавторов называется «Возникновение и возвращение инфекционных болезней: третий эпидемиологический переход», и в этом названии уже содержится развиваемая в статье мысль. В ней отмечаются три новые тенденции: 1) появление ранее неизвестных инфекционных заболеваний, становящихся причиной смерти взрослого населения; 2) рост заболеваемости существовавшими ранее инфекционными болезнями, которые считались поставленными под контроль; 3) способность многих появляющихся патогенов генерировать устойчивые к 
противомикробным препаратам штаммы быстрее, чем могут быть разработаны безопасные новые лекарства (Barrett et al. 1998: 256).

Авторы статьи были не первыми, кто указал на все эти тенденции и на опасность возвращения, казалось бы, оставшихся в прошлом, инфекционных угроз. Однако ранее авторы, также писавшие достаточно подробно об этих новых тенденциях, все же не были уверены в том, что они дают основание говорить об отдельном этапе эпидемиологической истории, скорее, склонялись к тому, что это не так (Olshansky et.al., 1997, Box 1). Баррет же и соавторы однозначно интерпретируют возрождение инфекционных угроз как наступление нового этапа, который они и называют «третьим эпидемиологическим переходом» (Barrett et al. 1998: 248).

Нельзя не согласиться с тем, что отмеченные тенденции указывают на новые угрозы и соответственно на новые вызовы для современных обществ. Но означают ли они также вызов эпидемиологической модели смертности, сложившейся в результате концептуализированного Омраном перехода?

Основания говорить о переходе появились тогда, когда впервые резко упала роль инфекционных заболеваний, «причем они не были заменены другими так, чтобы общая смертность в данном возрасте осталась на прежнем уровне. Повысился сам возраст смерти, и увеличилась продолжительность жизни. Термин эпидемиологический переход используется для обозначения перехода не только от одной доминирующей структуры патологии к другой, но также и радикальной трансформации в возрасте смерти» (Meslé, Vallin 2002: 440).

Эту мысль (которая, как мы видели, рассматривая вопрос о «кардиоваскулярной революции», была сильно недооценена самими Меле и Валленом) можно выразить еще более конкретно. Хотя в процессе эпидемиологического перехода изменения в смертности затрагивают всю возрастную шкалу, фундаментальное значение, особенно на первых этапах перехода, имеет снижение младенческой и детской смертности. Могут ли те вполне реальные угрозы, о которых встревоженно пишут многие авторы, реализовавшись, поколебать нынешнюю эпидемиологическую модель смертности? Есть ли основания предполагать, что инфекционные и паразитарные болезни вернут себе былую роль главного источника младенческой и детской смертности, за счет которой в прошлом в основном и поддерживалось долговременное равновесие высокой рождаемости и высокой смертности. Возможен ли дрейф кривой дожития к ее прежней форме?

Наверно, не следует недооценивать эпидемическую природу заразных болезней, их способность быстро распространяться в результате контактов между людьми и связанные с этим риски. Но если на минуту отвлечься от этой особенности инфекционных заболеваний, то, выступая в качестве причины смерти, они ничем не отличаются от любой другой причины. В соревновании с другими причинами, как мы видели на примере болезней системы кровообращения и рака, они могут выигрывать или проигрывать только в зависимости от того, каков средний возраст смерти от каждой из них. Если средний возраст смерти от инфекционных и паразитарных заболеваний становится примерно таким же, как и от большинства других причин смерти, эти заболевания «вписываются» в новую эпидемиологическую модель смертности, не противоречат ей, не говорят об откате назад 
или о переходе к какой-либо иной модели. Если эпидемиологический переход завершен в том смысле, в каком об этом говорилось выше, - то даже и увеличение смертности от инфекционных заболеваний в этом случае не дает оснований говорить о каком-либо новом переходе.

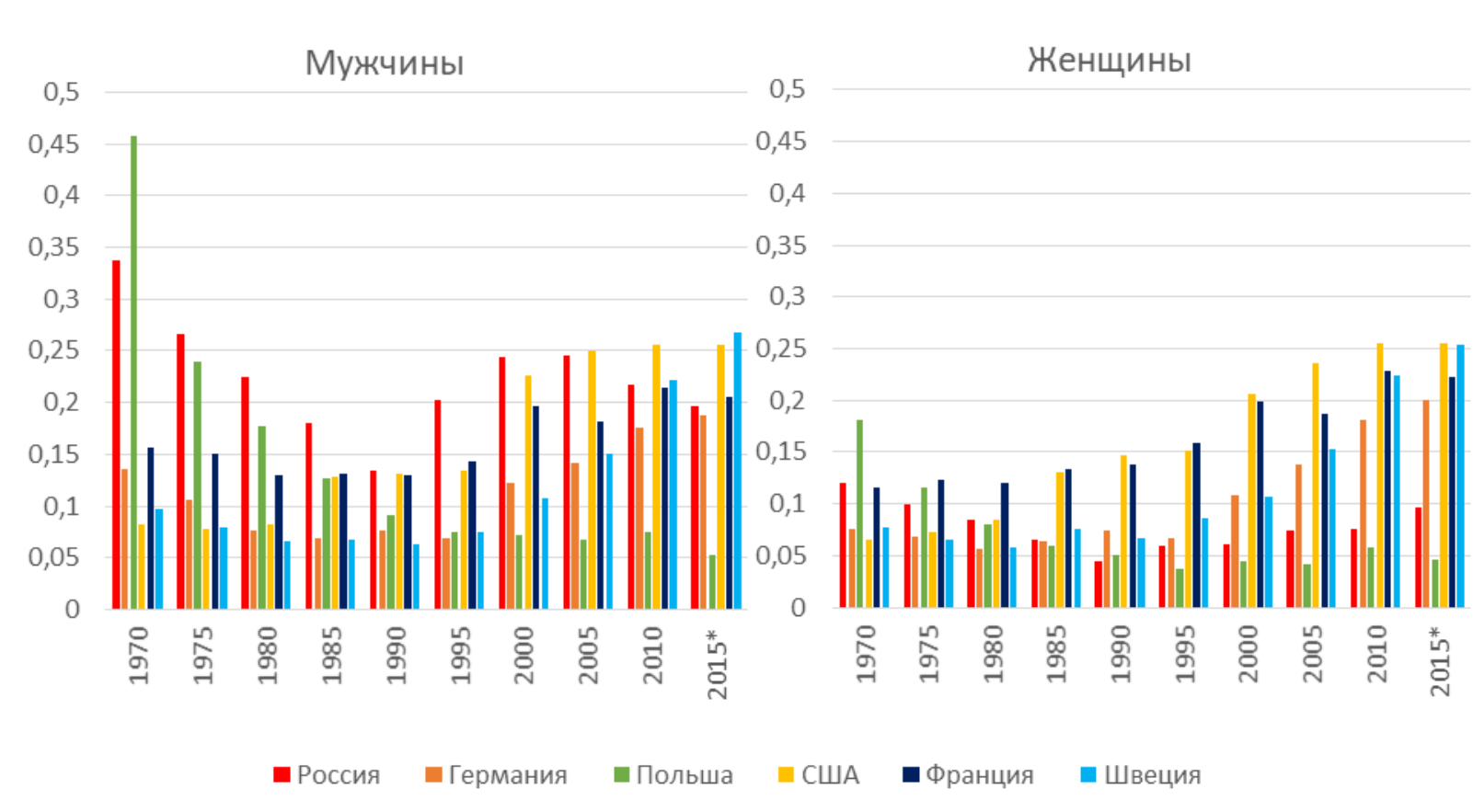

Рисунок 8. Вероятность для новорожденного умереть на протяжении жизни от инфекционного или паразитарного заболевания в некоторых странах, 1970-2015*

* Россия - 2019, Германия и Польша - 2016, США - 2013, Францฺия и Швеичия - 2015.

Источники: (Preston, Keyfitz, Schoen 1972; Human Cause-of-Death Database; WHO Mortality Database).

Инфекционные и паразитарные болезни нигде не исчезли полностью; даже в самых благополучных странах существуют и туберкулез, и СПИД, бывают и вспышки кори или других заразных болезней. Всем известны сезонные эпидемии гриппа. Среди названных Террисом групп причин смерти, в установлении контроля над которыми он видел задачу «второй эпидемиологической революции», основное место, как и у Омрана, занимали хронические заболевания и «рукотворные» внешние причины. Но на пятом месте в его списке - после болезней сердца, сосудов головного мозга, рака и внешних причин - стояли грипп и пневмония, роль которых, как он ожидал, будет снижаться благодаря антигриппозной вакцинации групп риска и улучшению терапии с применением антибиотиков.

Сейчас ясно, что такие ожидания были избыточно оптимистичными. На это указывают как уже упомянутое возвращение старых и появление новых инфекционных болезней, так и рост их устойчивости к лекарственным препаратам. Об этом же свидетельствует и статистика смертности в экономически развитых странах: вероятность умереть от инфекционных болезней, которая долгое время снижалась, стала увеличиваться (рисунок 8). 
Но та же статистика смертности указывает и на то, что одновременно с ростом вероятности умереть от инфекционных заболеваний увеличивается и средний возраст смерти от них (рисунок 9), т. е. что они все чаще становятся причиной смерти людей преклонного возраста, конкурируя в этом смысле с сердечно-сосудистыми или онкологическими заболеваниями, а не, скажем, с дифтерией или корью. Только Россия демонстрирует привычное для нее отставание. Если снова обратиться к данным по Англии и Уэльсу, то в 1861 г. средний возраст смерти от болезней системы кровообращения у мужчин был на 44,8 года выше, чем от инфекционных заболеваний, в 1960 г. - на 15,4 года выше, а в 2016 г. - всего на 2,5 года выше. Соответствующие разрывы для женщин - 47,0; 19,1; 3,6 года. Как видно на рисунке 4, в странах с низкой смертностью средний возраст смерти от инфекционных заболеваний часто выше, чем от рака.

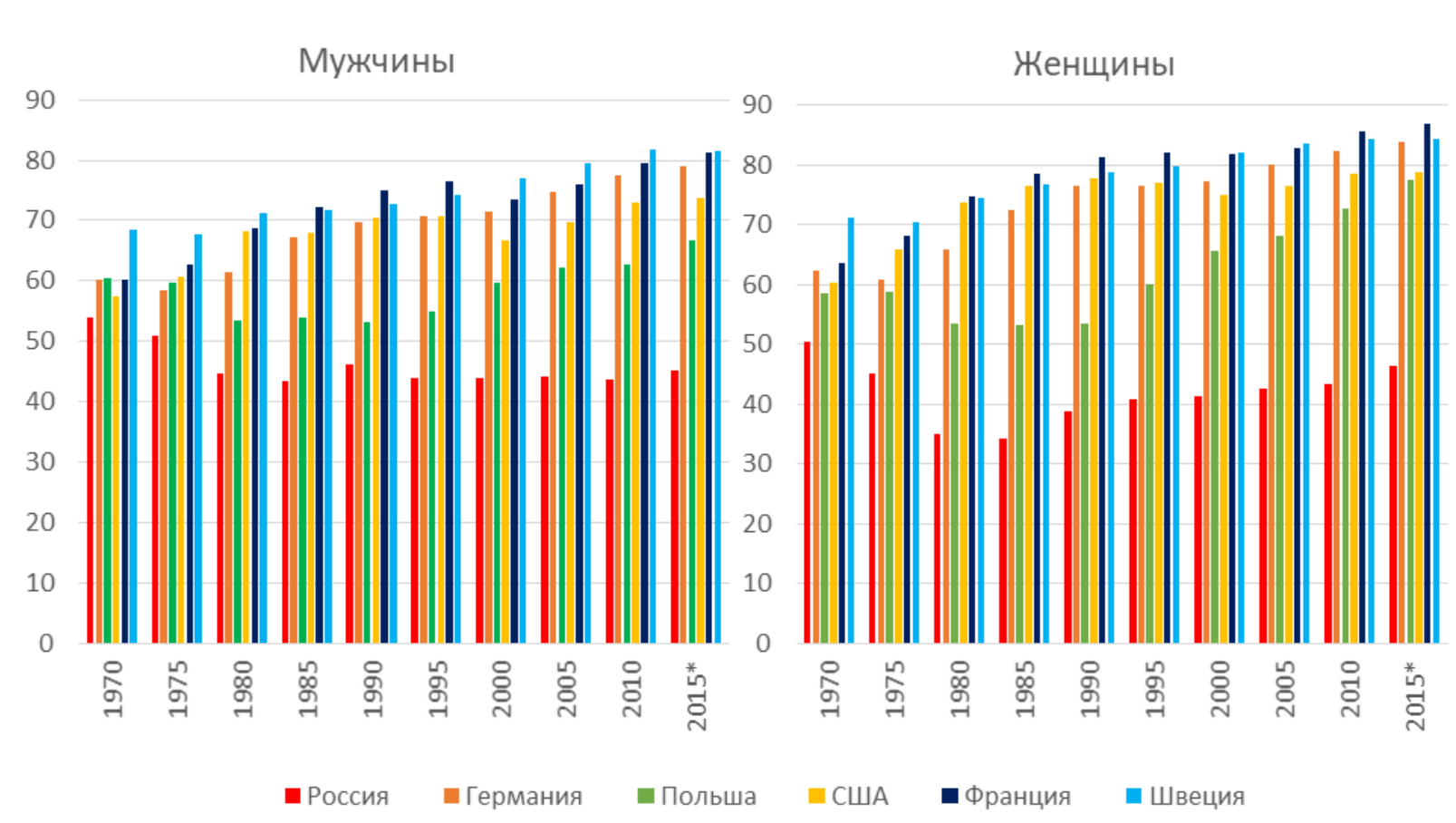

\section{Рисунок 9. Средний возраст смерти от инфекционных или паразитарных заболеваний в некоторых странах, 1970-2015*, лет}

* Россия - 2019, Германия и Польша -2016, США - 2013, Франция и Швеция - 2015.

Источники: (Preston, Keyfitz, Schoen 1972; Human Cause-of-Death Database; WHO Mortality Database).

А это говорит о продолжении и завершающих стадиях нынешнего эпидемиологического перехода, а никак не о начале нового. «Радикальной трансформации в возрасте смерти» (Meslé, Vallin 2002: 440) - упоминавшейся выше принципиально важной черты эпидемиологического перехода Омрана - в данном случае нет.

Даже COVID-19 - несомненное подтверждение верности всех тревожных предупреждений о возможном реванше инфекционных заболеваний - вполне вписался в нынешнюю эпидемиологическую модель смертности в том смысле, что он оказался почти безобидным для детей, а особенно опасным для пожилых и престарелых.

«Третий эпидемиологический переход» звучит эффектно, но нужно ли умножать сущности без надобности? Это не приближает к пониманию актуальных задач борьбы за 
человеческое долголетие, a, скорее, удаляет от него. Сейчас эти задачи связаны с реализацией нынешнего - и, повторю еще раз, пока единственного - эпидемиологического перехода.

\section{«ОБРАТНЫЙ ЭПИДЕМИОЛОГИЧЕСКИЙ ПЕРЕХОД»?}

«Обратный эпидемиологический переход в России» - название книги, в которой, как говорится в ее аннотации, «установлены общие и специфические закономерности развития эпидемиологического перехода в России вплоть до последней трети XX века, создавшие предпосылки для возможности обратного эпидемиологического развития... Обоснована принципиальная возможность обратного эпидемиологического перехода, которая реализуется в современной России» (Семенова 2005).

То, что Россия, как и другие европейские республики СССР, на протяжении десятилетий являла собой удивительный пример топтания на месте и даже отката назад во всем, что касалось показателей смертности и продолжительности жизни, - факт общеизвестный. Но как истолковать этот пример в контексте представлений об эпидемиологическом переходе? Действительно ли существует принципиальная возможность «обратного перехода»?

Есть авторы, которые убеждены, что такая возможность существует, «эволюционные изменения в моделях заболеваемости и смертности обратимы, уступая место тому, что можно было бы назвать «обратным переходом» и что это должно быть отражено в исходной теории» (Frenk et al. 1989: 31). Омран тоже полагал, что «откат («обратный переход») или стагнация перехода возможны во время эпидемий, экономических, политических, экологических или других кризисов» (Omran 1998: 100; Омран 2019: 179).

С тем, что временный «откат» во время кризисов возможен, трудно не согласиться. Намного труднее допустить попятное эволюционное движение. Что считать индикатором такого попятного движения, в чем оно может проявляться? Известные нам поиски ответа на этот вопрос едва ли можно считать успешными.

Когда В. Семенова, посвятившая «обратному переходу» в России целую книгу, в заключение подчеркивает, что его индикатором не может быть «сам по себе рост смертности от той или иной причины» (Семенова 2005: 266), то это, скорее, уход от ответа, чем ответ. Конъюнктурный, относительно кратковременный рост смертности возможен всегда, но это может не иметь никакого отношения к эпидемиологическому переходу. Если же действительно происходит полный или хотя бы частичный возврат к прежней эпидемиологической модели - только в таком случае можно говорить об обратном переходе - то об этом, в первую очередь, должно сигнализировать именно повышение смертности, и оно должно быть значительным и устойчивым. Если же такого повышения нет, то нет и оснований говорить об «обратном переходе». Но, - здесь можно согласиться с В. Семеновой - таких оснований нет и в том случае, если смертность повышается и при этом не в ситуации социального кризиса. Пандемия коронавируса может привести к 
повышению смертности, но она едва ли может коренным образом изменить уже сложившуюся эпидемиологическую модель смертности.

Заведомо понятно, что эпидемиологический переход - это исторический процесс, имеющий собственные детерминанты и растянутый во времени. Он не может быть абсолютно независимым от других протекающих в обществе процессов - экономических, политических и др., они могут ускорять и тормозить его. Если страна проходит через период политического кризиса, экономического и социального застоя, то это не может не затормозить и эпидемиологический переход, и тогда индикаторы этого перехода одновременно становятся индикаторами общей ситуации в стране. Применительно к России это хорошо видно на примере динамики младенческой смертности - не единственного, но одного из главных, если не самого главного индикатора эпидемиологического перехода.

Во второй половине XIX века в странах Западной Европы именно снижение младенческой смертности стало наиболее заметным признаком нового демографического порядка. В 1900 г. в Европе было всего две страны (Норвегия и Швеция), где коэффициент младенческой смертности опустился чуть ниже 100 на 1000 родившихся - по тем временам очень низкий показатель. В России в это время он составлял 250 на 1000, здесь едва ли можно было говорить даже о начале перехода. К 1950 г. этот коэффициент в Норвегии упал до 28,2, в Швеции - до 21,0, но и в России он снизился до 88,4, стало быть, эпидемиологический переход пришел и в Россию. Ей было еще далеко до Швеции, но она была близка к Португалии, тоже западноевропейской стране, хотя по тем временам и отсталой.

Примерно до середины 60-х годов младенческая смертность в России снижалась намного быстрее, чем в Португалии, и разрыв между ними - в пользу России увеличивался. Но затем наша страна вступила в полосу застоя, в 1982 г. Португалия обогнала Россию, стал нарастать разрыв теперь уже в пользу Португалии (рисунок 10). Невинный, казалось бы, показатель младенческой смертности оказался надежным маркером общего положения в стране. Стагнация и даже рост этого показателя в 1970-е годы дали основания для пророческого предсказания Э. Тодда по поводу всей советской политической системы ${ }^{5}$. Но и тогда никакого обратного эпидемиологического перехода не было, переход лишь замедлился, и сближение российского показателя с теперь уже низким португальским или шведским лишь отодвинулось на более поздний срок.

${ }^{5}$ «В брежневском СССР растущая частота насильственных смертей сопровождается новым явлением, ростом детской смертности... Государство уже не способно к позитивным действиям... Невозможно предвидеть, в какой форме выразится советский кризис и выльется или нет разложение, характерное для этой системы сейчас, во всеобщий спазм - реформистский, революционный или военный. Но мы уже можем констатировать первое проявление кризиса - санитарный регресс и рост насильственной смертности...

Распад первой из коммунистических систем уже начался» (Todd 1990: 333). (В издании 1990 г. воспроизводится текст выступления 1978 г., опубликованный в 1980 г. в журнале «Economie et humanisme», № 252). 


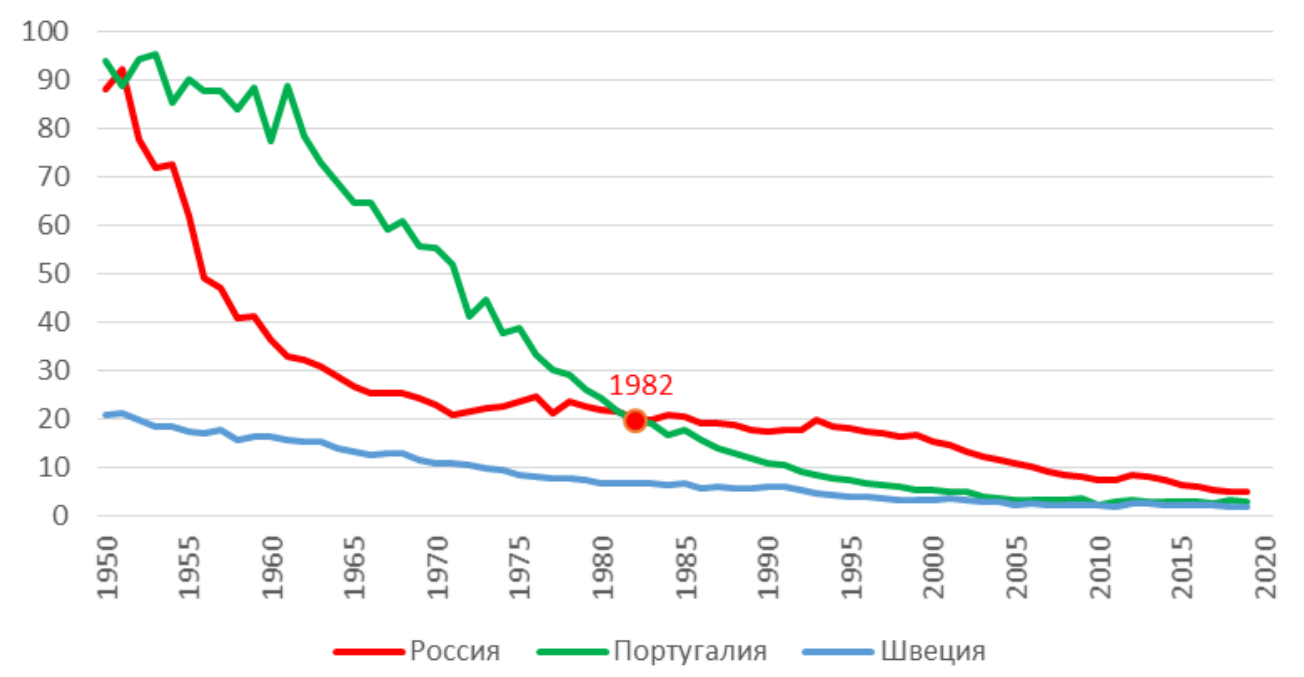

\section{Рисунок 10. Младенческая смертность в России, Португалии и Швеции, 1950-2019, на 1000 родившихся}

Источник: (Демоскоп Weekly).

Незавершенность эпидемиологического перехода как длящегося и растянутого во времени процесса - нормальное состояние. Оно может преодолеваться более быстро или более медленно в зависимости от общих темпов модернизации того или иного общества. Контрмодернизационные тенденции в экономике, общественной жизни, культуре, политике могут тормозить эпидемиологический переход. Но, если исключить глобальные катастрофы непоправимых масштабов, серьезного попятного движения, возврата к моделям, существовавшим даже в начале XX века, быть не может. Эпидемиологический переход необратим.

\section{ЭПИДЕМИОЛОГИЧЕСКИЙ ПЕРЕХОД В РАЗВИВАЮЩИХСЯ СТРАНАХ}

Предложенная Омраном концепция эпидемиологического перехода отражала опыт, накопленный в экономически развитых странах, причем не только в европейских странах классического перехода, но и в такой стране, как Япония, где переход начался позднее, но шел ускоренными темпами.

Для развивающихся же стран, отмечал Омран, был типичен «сравнительно недавний и еще не завершенный эпидемиологический переход» (Omran 1971: 535; Омран 1977: 88), который он характеризовал как «замедленный». Тогда же он отмечал, что, несмотря на сходство тенденций в развивающихся странах Латинской Америки, Азии и Африки, между ними все же имеются существенные различия (Omran 1971: 536; Омран 1977: 89). По мере того, как эпидемиологический переход в развивающемся мире набирал силу, полнее проявлялись связанные с этими различиями реальные проблемы, и в своей статье 1998 г. Омран привел более пространную и детализированную схему «незападных» моделей перехода (Omran 1998; Омран 2019).

Неудивительно, что в это время интерес к проблемам развивающихся стран повышался и у других исследователей, и неизбежно они снова и снова обращались к 
концепции Омрана. Но, странным образом, использование этой концепции почти всегда сопровождалось критикой в адрес ее создателя, часто совершенно несправедливой, а главное, свидетельствовавшей об отказе от использования тех познавательных возможностей, которые в ней заложены.

В 2014 г. вышел специальный номер журнала «Global Health Action» под общим названием «Эпидемиологические переходы - за пределами теории Омрана» (Epidemiological Transitions - Beyond Omran's Theory), главное внимание в нем сосредоточено на актуальных проблемах развивающихся стран.

Автор вступительной статьи к номеру приходит к выводу, что концепция эпидемиологического перехода «была релевантна как способ описания и, в известной степени, понимания закономерностей связи между моделями заболеваемости и смертности и изменениями населения в западных обществах до 1950-х годов, а не как универсальное описание или предсказание, облегчающее выработку политики здравоохранения в современных обществах или в развивающихся странах» (Defo 2014a: 13).

Вывод о «нерелевантности» теории Омрана применительно к развивающимся странам делается, в частности, на основании проверки семи гипотез, которые якобы вытекают из теории эпидемиологического перехода, но не подтверждаются опытом Африки. Приведем, для примера, одну из этих гипотез и ее проверку.

Гипотеза 4: «В соответствии с теорией эпидемиологического перехода Омрана, смертность от инфекционных заболеваний в незападных странах, согласно прогнозам, должна была снизиться с 42,1\% всех смертей в менее развитых регионах в 1970 г. до 19,4\% в 2015 г., в результате чего ожидаемая продолжительность жизни при рождении должна увеличиться с 57,5 до 68,5 года».

Проверка гипотезы 4: «Африка стоит далеко от остального мира... Только инфекционные и паразитарные заболевания служат причиной $41 \%$ всех смертей в Африке по сравнению с 15\% в мире в целом... 64\% всех случаев смерти в мире вызваны неинфекционными заболеваниями; этот показатель составляет $87 \%$ в развитых регионах и $28 \%$ в Африке. В большинстве развивающихся регионов вклад неинфекционных заболеваний (причины смерти группы II) превосходил вклад причин смерти группы I уже в 1990 г., тогда как в Африке южнее Сахары это соотношение составляло всего 0,4... Почти 20 лет спустя это соотношение по-прежнему составляет 0,4 для Африки по сравнению с 2,4 в мире в целом, 12,4 в развитых странах, 11,9 в Восточной Азии, 4,9 в Латинской Америке и Карибском бассейне и 1,4 в Южной Азии».

Неужели действительно теория эпидемиологического перехода, указывающая на закономерное снижение доли смертей от инфекционных заболеваний как глобальную тенденцию, должна позволять предвидеть это снижение с точностью до десятых долей процента к определенной дате для целых континентов? По-видимому, автор статьи считает, что это так, потому что именно так он формулирует свою «гипотезу 4» и, естественно, приходит к выводу, что «гипотеза 4 в Африке не подтверждается» (Defo 2014b).

Сумма же таких выводов приводит к общему заключению о непригодности современных теоретических подходов для анализа демографической ситуации в Африке и 
демографических перспектив этого континента. «В целом предполагаемые связи между смертностью, рождаемостью и ростом населения не находят эмпирического подтверждения в большей части Африки, что ставит под сомнение основную предпосылку концепции перехода, воплощенной в моделях демографического, эпидемиологического и санитарного переходов. Несмотря на признаки начала снижения рождаемости в нескольких африканских странах, увеличивающийся разрыв между моделями рождаемости и смертности внутри стран и между ними в сочетании с устойчивой распространенностью инфекционных заболеваний на континенте свидетельствует о том, что для понимания тенденций в области здоровья и болезней в Африке требуется иной, новый подход» (Defo 2014b).

\section{Действительно ли это так?}

Африка, родина Человечества, сейчас в самом деле самый слаборазвитый континент мира. Однако это не значит, что в Африке не действует закон всемирного тяготения или неверна таблица Менделеева. Демографическая теория устанавливает закономерности, общие для всех, это относится и к теории эпидемиологического перехода. Как отмечалось выше, ее смысловая доминанта (надо признать, очень плохо артикулированная Омраном), заключается не просто в том, что одни болезни и причины смерти заменяются другими, а в том, что их новый набор резко сдвигает вверх возраст смерти подавляющего большинства людей и в результате меняется вся демографическая картина мира. Это предсказание универсально: если эпидемиологический переход вообще имеет место, он не может происходить по-иному ни в развитых странах, ни в развивающихся. Различаться, т. е. быть более долгими и тернистыми, либо менее долгими и тернистыми в зависимости от исторических обстоятельств могут лишь пути движения к сходному результату. А на это различие путей Омран как раз постоянно указывал, говоря о разных моделях перехода

К сожалению, ни сам Омран, ни его последователи или критики, рассуждая о развивающихся странах, не используют в явном виде понятия догоняющъий эпидемиологический переход, хотя, по существу, они постоянно оперируют фактами, указывающими именно на такую его природу. Это особенно ясно в тех случаях, когда они пишут о «наложении» одних стадий перехода на другие. Подобное наложение как раз и возникает в силу того, что разные стадии перехода реализуются не последовательно, как это было (и не могло быть иначе) в странах-первопроходцах, а параллельно - благодаря заимствованию и неравномерному освоению уже готовых медицинских технологий и социальных практик. Сосуществование во времени разных стадий перехода свидетельство его незавершенности.

Именно это имел в виду Омран, когда писал о тройном бремени проблем, связанных со здоровьем, в незападных обществах на разных стадиях перехода. «Это влечет за собой, по крайней мере, три основных бремени для здоровья, накладывающихся друг на друга: нерешенные старые проблемы со здоровьем; появление новых проблем; плохо подготовленная система здравоохранения и низкая подготовка медицинский кадров» (Omran 1998: 106; Омран 2019: 190).

Это совершенно верное рассуждение подтверждалось опытом многих «догоняющих» стран, на него указывал, например, анализ незавершенного 
эпидемиологического перехода в позднем СССР на рубеже 1980-1990-х годов. «Незавершенность объясняется двумя причинами: 1) не до конца решены основные задачи ранних этапов эпидемиологического перехода и сохраняются элементы традиционной структуры патологии и причин смерти... 2) по мере завершения эпидемиологического перехода (второй эпидемиологической революции) не развернута в достаточной степени борьба против патогенных факторов, опасных на новом этапе развития». На общую незавершенность эпидемиологического перехода в СССР накладывались региональные контрасты - следствие того, что разные республики СССР находились на разных этапах перехода (Вишневский, Школьников, Васин 1991:1014; Vishnevsky, Shkolnikov, Vassin 1991: 93). Из этого делался вывод, что в одних республиках, в которых проживало 75\% населения СССР, «эпидемиологический переход продвинулся наиболее далеко, явно преобладала «новая» патология и основные усилия должны быть направлены на борьбу именно с ней. Для этого необходима новая стратегия отстаивания здоровья и жизни людей. В остальных республиках положение далеко не столь ясно, еще очень крепки, особенно у сельского населения, элементы «старой» патологии, и пока еще сохраняет свое значение прежняя стратегия» (Вишневский, Школьников, Васин 1991:1020-1021; Vishnevsky, Shkolnikov, Vassin 1991: 95). Отмеченные различия объяснялись «неравномерностью эпидемиологического перехода различных групп населения» (Вишневский, Школьников, Васин 1991:1014; Vishnevsky, Shkolnikov, Vassin 1991: 82) и воспринимались не как показатель несостоятельности или неполноты теории Омрана, а, скорее, как подтверждение ее объяснительно силы.

Между тем в литературе факт «перекрытия» одних стадий перехода другими, обнаруженный, например, в Мексике, рассматривается как не соответствующий теории, требующий ее модификации (Frenk et al. 1989: 31). Это еще один из многих примеров того, как от общей теории требуют способности предсказать в деталях любую конкретную ситуацию и чуть ли не дать инструкцию по «выработке политики здравоохранения» для каждой страны. Можно ли предъявлять такие требования к теории? Теория может вообще не иметь непосредственного прикладного значения, но иметь мировоззренческий смысл, способствовать лучшему пониманию объективных процессов, и это само по себе очень важно. Мне кажется, что обобщение Омрана имеет такое смысловое значение, оно высветило очевидное для всех снижение смертности как некий целостный и закономерный исторический феномен. Но это обобщение важно также и для практической деятельности, оно дает ориентиры для выбора приоритетов на разных этапах эпидемиологического перехода, позволяет формулировать его прогноз.

Другое дело, что для практической деятельности одной универсальной стратегии, основанной на общей, пусть и верной теории, недостаточно, всякий раз нужна определенная тактика действий, учитывающая множество конкретных обстоятельств, от которых теория как раз и абстрагируется для того, чтобы выйти на самый высокий уровень обобщения. В жизни нужны и стратегия, и тактика, но стратегия важнее. Если воспользоваться словами Клаузевица, то «стратегия - учение об использовании боев в целях войны», а тактика - это «учение об использовании вооруженных сил в бою» (Клаузевиц 2017). Победить в бою важно, но главное - это выиграть войну. 
Безграничное разнообразие климатических, гигиенических, экономических, социально-политических, социокультурных и прочих условий делает неизбежным и столь же безграничное разнообразие тактик реализации эпидемиологического перехода, его «моделей», выражаясь словами Омрана. В выработке таких тактик его теория - плохой помощник, но она на это и не претендует. Эта теория говорит только об одном, но важном. Если не считать развивающиеся страны вообе не способными совершить эпидемиологический переход, то рано или поздно, преодолев огромные трудности, они придут именно к тому, что предсказывал Омран: к новой эпидемиологической модели заболеваемости и смертности, при которой показатели продолжительности общей и здоровой жизни станут примерно такими же, как в развитых странах, а главными препятствиями дальнейшему улучшению этих показателей станут хронические заболевания и антропогенные факторы среды.

Сейчас этого еще не произошло, но продолжительность жизни в менее развитых, а особенно в наименее странах растет быстрее, чем в развитых, и тенденция к сближению показателей очевидна (рисунок 11).

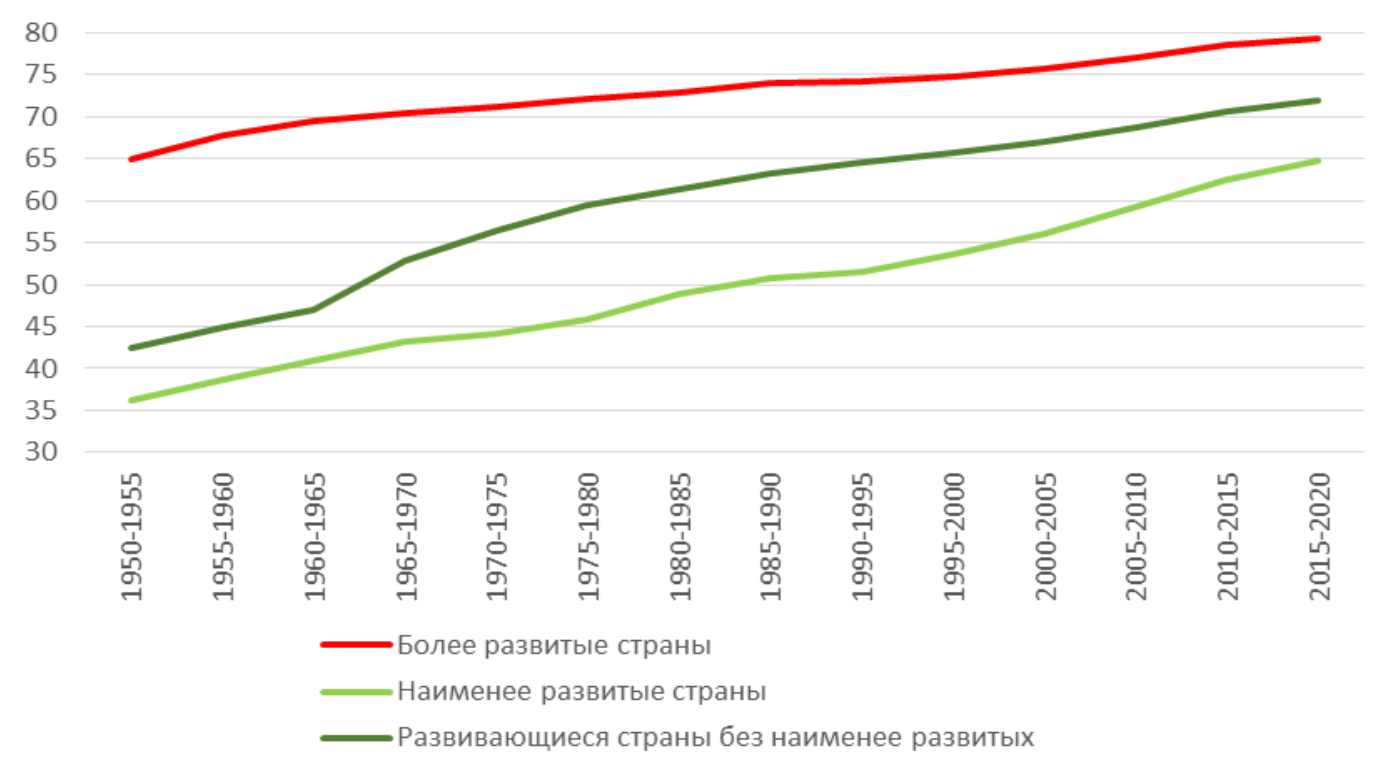

\section{Рисунок 11. Ожидаемая продолжительность жизни при рождении в развитых, менее развитых и наименее развитых странах, лет}

Источник: (World Mortality Report 2019).

Из 48 наименее развитых стран 34 находятся в Африке, как уже отмечалось, это наименее развитый регион мира, в том числе и с точки зрения продвижения африканских стран по пути эпидемиологического перехода. Тем не менее сказать, что в Африке в этом смысле ничего не меняется и она движется по пути, совершенно отличному от того, что описал Омран, было бы большим преувеличением.

Если верить оценкам ООН, то младенческая смертность в Африке к югу от Сахары в 2015-2020 гг. (51 на 1000 родившихся) была вдвое ниже, чем в самых продвинутых европейских странах на рубеже XIX и XX веков или в СССР в 1950 г., и почти в 5 раз ниже, чем в России в конце XIX века. В самом регионе она снизилась с середины XX века почти 
в 3,5 раза (UN WPP-2019, файл MORT/F01-1), за таким снижением не могут не стоять значительные изменения в эпидемиологической модели смертности. Другое дело, что они недостаточны и африканские страны все еще находятся на ранних стадиях эпидемиологического перехода, по пути которого идут заметно обгоняющие их другие развивающиеся страны (рисунок 12). Но это не основание, чтобы отрицать генеральную линию их движения, которая как раз и характеризуется в обобщенном виде теорией эпидемиологического перехода.
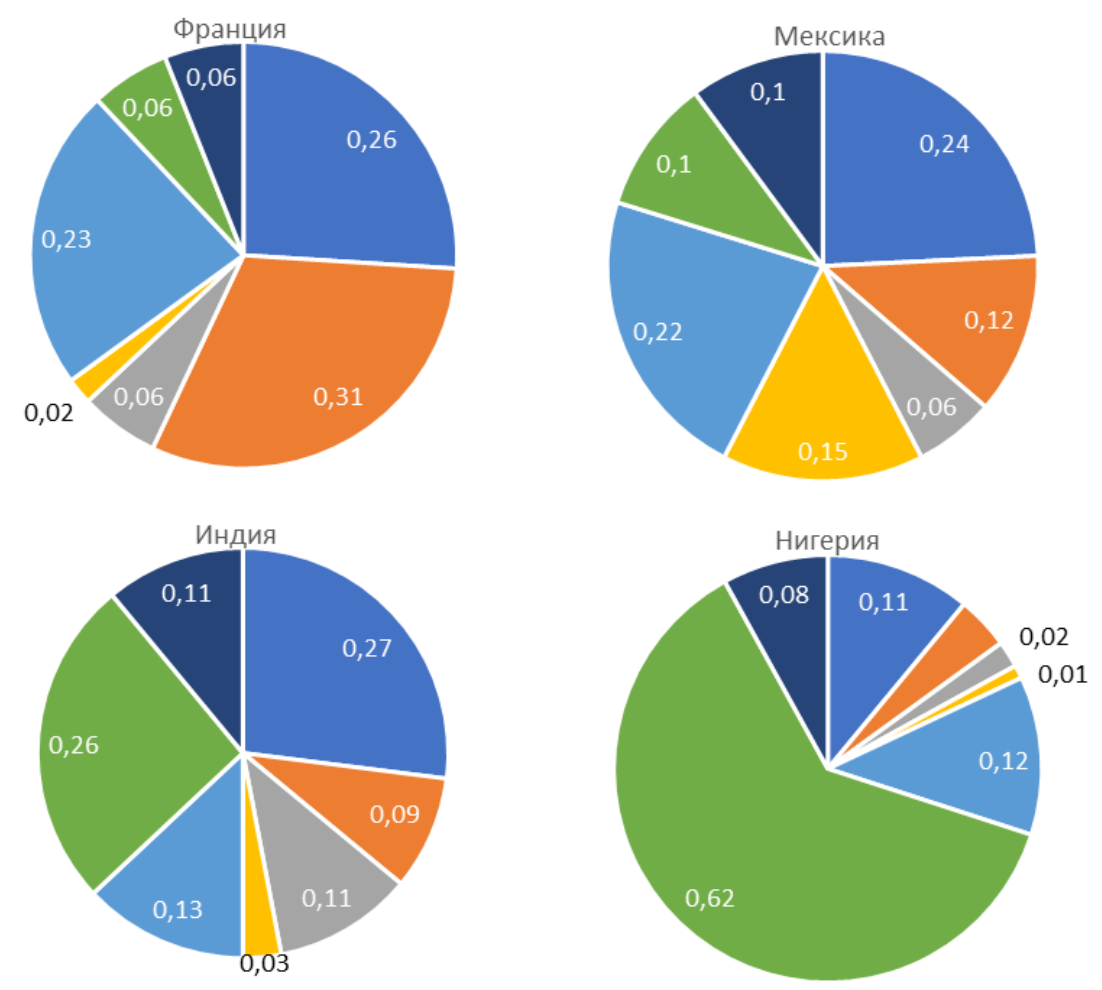

- Болезни системы кровообращения

- Новообразования

- Хронические болезни органов дыхания

- Диабет

- Другие неинфекционные

- Инфекционные, материнские, перинатальные, условия питания

- Внешние причины

\section{Рисунок 12. Структура смертности по причинам смерти во Франции, Мексике, Индии и Нигерии, 2016}

Источник: (WНО 2018).

\section{ЗАКЛЮЧЕНИЕ}

Появление концепции эпидемиологического перехода стало важным этапом в развитии научных представлений о демографическом переходе в целом. До этого на протяжении нескольких десятилетий внимание исследователей демографического перехода было полностью сосредоточено на изучении рождаемости и поисках объяснений ее снижения (об этом, кстати, упоминает и Колдуэлл (Caldwell 2001: 159)). 
Конечно, исследователи знали и о снижении смертности, в той или иной мере учитывали его при построении своих объяснительных схем - см. напр., (Davis 1963), хотя, как мне представляется, с большой неполнотой (Вишневский 2017). Но с точки зрения общей логики теории демографического перехода достаточно было указать на «переход в смертности» (mortality transition), ответом на который стал «переход в рождаемости» (fertility transition). Переход в смертности можно изучать, анализируя его количественные результаты, изменение показателей смертности, что и делается достаточно успешно. В качестве примера такого анализа можно привести исследование снижения смертности с середины XVIII века в Финляндии (Kannisto, Nieminen, Turpeinen 1999) или анализ ректангуляризации кривой дожития во Франции в XX веке (Robine 2001). Авторы этих исследований соотносят свои результаты со стадиями эпидемиологического перехода, выделенными Омраном, но это просто дань сложившемуся в литературе дискурсу, который в это время уже не мог обходиться без ссылок на концепцию Омрана.

Причины снижения смертности не вызывали больших вопросов, казалось достаточным указать на экономические, гигиенические, общекультурные изменения, в лучшем случае конкретизировать причины снижения смертности, как это сделали, например, МакКаун с соавторами (McKeown, Brown, Record 1972). Они пришли к выводу, что снижение смертности в Западной Европе в XIX веке было обусловлено главным образом повышением уровня жизни и успехами сельского хозяйства, что привело к улучшению питания, изменениям гигиенических условий, благодаря чему, в частности, снизилась смертность от кишечных инфекций, возможно, также имели значение причины, не зависящие от действия людей, например снижение вирулентности болезнетворных бактерий.

Для Ноутсайна и других теоретиков демографического перехода был важен сам факт снижения смертности, но Омран пошел дальше, задумавшись над природой этого снижения. «Подход Ноутстайна к анализу смертности наиболее полно разработан в эпидемиологии изменений населения Омрана, признающей, что... переход в смертности включает в себя нечто большее, чем просто количественное снижение уровней смертности и ослабление их кратковременных колебаний... Главная черта, отделяющая эпидемиологический переход от демографического перехода - добавление нового элемента, изменения структуры причин смерти закономерности и характеристика этапов перехода по конфигурациям причин смерти, а также по влиянию на них» (Defo 2014b). «Концепция эпидемиологического перехода помогает понять «анатомию» исторических изменений смертности именно как самостоятельной революции, приведшей к коренному изменению... структуры <причин смерти>» (Вишневский 2017: 10).

Омран всего лишь немного сместил угол зрения и взглянул на происходившие со смертностью изменения не со стороны их причин, а со стороны результата, который он увидел в обобщенном виде: не как сумму выигрышей от снижения смертности от туберкулеза, детских инфекций, желудочных заболеваний, материнской смертности и др., а как общий качественный сдвиг, за короткое время принципиально изменивший всю эпидемиологическую картину. В этом и заключалось открытие, смысл которого абсолютно точно выражен двумя словами: эпидемиологический переход. 
Возможно, это открытие Омран сделал по воле случая и было бы более справедливо, если бы такая удача выпала на долю того же МакКауна или, скажем, Фрэнка Ноутстайна или Кингсли Дэвиса. Но она досталась Омрану, и этот факт уже нельзя отменить.

Коль скоро это произошло, Омран стал «классиком цитирования» не случайно. Ни один исследователь, изучающий историческую или современную эволюцию здоровья и смертности в широком социобиологическом контексте, не может обойти плодотворную, хотя и оказавшуюся не очень простой концепцию эпидемиологического перехода, не попытаться использовать ее аналитический и прогностический потенциал.

Но отсюда и возможные издержки. Омран сформулировал концепцию в самом общем виде, многие высказанные им положения не безупречны, концепция в целом нуждается в развитии. Необходимо более глубокое пониманию механизмов становления и эволюции современной эпидемиологической модели заболеваемости и смертности, ее «двухмерности», внутренних взаимосвязей, возможных вариантов и ограничений, видимо, и способов ее защиты перед лицом вероятных угроз. Решение этих задач может быть успешным, только если держать в поле зрения весь целостный процесс трансформации двухмерной эпидемиологической модели заболеваемости и смертности - трансформации, которую и подразумевает концепция эпидемиологического перехода.

А все попытки переиначить, раздробить или переименовать эту концепцию или использовать ее не по назначению - это не слишком эффективные попытки женихов Пенелопы натянуть лук Одиссея.

\section{БЛАГОДАРНОСТИ}

Автор благодарит Е.М. Андреева и А.Е. Щура за помощь в подготовке данных о смертности по причинам смерти.

\section{ЛИТЕРАТУРА}

Андреев Е.М., Вишневский А.Г., Шабуров К.Ю. (1986). Продолжительность жизни и причины смерти. В А.Г. Волков (Ред.), Демографические проиессы и их закономерности (сс. 110-130). М.: Мысль.

Вишневский А.Г. (1973). Демографическая революция. Вопросы философии, 2, 53-64.

Вишневский А.Г. (1976). Демографическая револючия. М.: Статистика. 238 с.

Вишневский А.Г. (2017). Нерешенные вопросы теории демографической революции. Население и экономика, 1(1), 3-21.

Вишневский А.Г. (2018). Демографический переход и гипотеза гиперболического роста населения. Демографическое обозрение, 5(1), 64-105. URL: https://doi.org/10.17323/demreview.v5i1.7710

Вишневский А.Г., Школьников В.М., Васин С.А. (1991). Эпидемиологический переход и причины смерти в СССР. Экономика и математические методы, 27(6), 1013-1021. 
Вишняцкий Л.Б. (2000). «Верхнепалеолитическая революция»: география, хронология, причины. Stratum Plus, Археология и культурная антропология, 245-271.

Гаврилов Л.А. (1984). Существует ли предел продолжительности жизни организмов? Биофизика, 29(5), 908-909.

Гаврилов Л.А., Гаврилова Н.С. (1986). Биология продолжительности жизни: количественные аспекты. М., Наука.

Демоскоп Weekly. Приложение. Таблица Коэффициент младенческой смертности. URL: http://www.demoscope.ru/weekly/app/app4009.php

Клаузевиц К. (2017). О войне. Избранное. М.: Издательство АСТ.

Ливи Баччи М. (2010). Демографическая история Европы. СПб.: Александрия.

Омран А.Р. (2019). Теория эпидемиологического перехода: взгляд 30 лет спустя. Демографическое обозрение, 6(1), 177-216. URL: https://doi.org/10.17323/demreview.v6i1.9117

Омран А. Р. (1977). Эпидемиологический аспект теории естественного движения населения. В Д.И. Валентей, А.П. Судоплатов (Ред.), Проблемы народонаселения. $O$ демографических проблемах стран Запада (с. 57-91). М.: Прогресс.

Павлик 3. (1979). Проблемы демографической революции. В А.Г. Вишневский, И.С. Кон (Ред.), Брачность, рождаемость, семья за три века (с. 158-168). М.: Статистика.

Паевский В.В. (1970). Таблицы смертности населения СССР. В А.М. Мерков (Ред.), Вопросы демографической и медицинской статистики (Избранные произведения) (с. 228-307). М. Статистика.

Семенова В.Г. (2005). Обратный эпидемиологический переход в России. М.: ЦСП.

Шнирельман В.А. (1986). Демографические и этнокультурные процессы эпохи первобытной родовой общины. В Ю.В. Бромлей, История первобытного общества. Эпоха первобытной родовой общины (с. 427-489). М.: Наука.

Acsadi G., Nemeskéri J. (1970). History of human life span and mortality. Budapest: Akadémiai kiadó.

Barrett R., Kuzawa C.W., McDade T., Armelagos G.J. (1998). Emerging and re-emerging infectious diseases: the third epidemiologic transition. Annual review of anthropology, 27(1), 247-271.

Birabin J.-N. (2006). The History of the Human Population from the First beginnings to the Present Day. In G. Caselli, J. Vallin, G. Wunsh (Eds.), Demography: Analysis and Synthesis. A Treatise in Population Studies (Vol.3, Ch. 66). Academic Press.

Caldwell J.C. (2001). Population heath transition. Bulletin of the World Health Organization, 79, $159-160$.

Caldwell J.C., Caldwell B.K. (2003). Was there a Neolithic mortality crisis? Journal of Population Research, 20(2), 153-168.

Chesnais J.-C. (1986). La transition démograhique. Etapes, formes, implications écpnomiques. PUF.

Coleman D. (2004). Migration in the 21st century: a third demographic transition in the making? Plenary Address to the British Society for Population Studies Annual Conference, Leicester, 13 September 2004. 
Davis K. (1944). Demographic fact and policy in India. Demographic Studies of Selected Areas of Rapid Growth. The Milbank Memorial Fund Quarterly, 22(3), 256-278.

Davis K. (1945).The World Demographic Transition. The Annals of the American Academy of Political and Social Science, 237, 1-11.

Davis K. (1963). The theory of change and response in modern demographic history. Population Index, 29(4), 345-366.

De Flora S., Quaglia A., Bennicelli C., and Vercelli M. (2005). The epidemiological revolution of the 20th century. The FASEB Journal, 19, 892-897.

Deevey E.S. (1960). The human population. Scientific American, 203(3), 194-205.

Defo B.K. (2014a). Beyond the 'transition' frameworks: the crosscontinuum of health, disease and mortality framework. Global Health Action, 7(1), 24804. URL: https://doi.org/10.3402/gha.v7.24804

Defo B.K. (2014b). Demographic, epidemiological, and health transitions: Are they relevant to population health patterns in Africa? Global Health Action, 7(1), 24804. URL: https://doi.org/10.3402/gha.v7.22443

Eggleston K.N., FuchsV.R. (2012). The new demographic transition: Most gains in life expectancy now realized late in life. Journal of Economic Perspectives, 26(3), 137-156.

Fihel A., Pechholdova M. (2017). Between 'Pioneers' of the Cardiovascular Revolution and Its 'Late Followers': Mortality Changes in the Czech Republic and Poland Since 1968. Eur J Population, 33, 651-678. URL: https://doi.org/10.1007/s10680-017-9456-y

Freedman R. (Ed.) (1964). Population: The Vital Revolution. Garden City, New York: Doubleday \& Co.

Frenk J., Bobadilla J.L., Sepulveda J., Cervantes M.L. (1989). Health transition in middleincome countries: New challenges for health care. Health Policy and Planning, 4(1): 29-39. DOI: $10.1093 / \mathrm{heapol} / 4.1 .29$

Frenk J., Bobadilla J.L., Stern C., Frejka T., Lozano R. (1991). Elements for a theory of the health transition. Health Transition Review, 1(1), 21-38.

Human Cause-of-Death Database. French Institute for Demographic Studies (France) and Max Planck Institute for Demographic Research (Germany). Available at www.causeofdeath.org

Kannisto V., Nieminen M., Turpeinen O. (1999). Finnish Life Tables since 1751. Demographic Research, 1. DOI: 10.4054/DemRes.1999.1.1.

Landry A. (2019). La révolution démographique. Études et essais sur les problèmes de la population. Paris: Ined Éditions.

Mackenbach J.P. (1994). The epidemiologic transition theory. Journal of Epidemiology and Community Health, 48, 329-332.

McEvedy C., Jones R. (1978). Atlas of World Population History. Penguin Books.

McKeown T., Brown R.G., Record R.G. (1972). An interpretation of the modern rise of population in Europe. Population Studies, 26(3), 345-382.

Meslé F., Vallin J. (2002). La transition sanitaire : tendances et perspectives. In G. Caselli, J. Vallin, G. Wunsch (Eds.), Démographie : analyse et synthèse (V. III. Ch. 57). INED.

Meslé F., Vallin J. (2006). The health transition: Trends and prospects. In G. Caselli, J. Vallin, G. Wunsh (Eds.), Demography: Analysis and Synthesis. A Treatise in Population Studies (V.2, Ch. 57). Academic Press. 
Notestein F.W. (1945). Population - the long view. In Th.W Schults (Ed.), Food for the world (37-57). Chicago University Press.

Olshansky S. J., Ault A.B. (1986). The fourth stage of the epidemiologic transition: The age of delayed degenerative diseases. The Milbank Quarterly, 64(3), 355-391.

Olshansky S. J., Carnes B., Rogers R.G., Smith L. (1997). Infectious diseases - new and ancient threats to world health. Population bulletin, 52, 2.

Omran A.R. (1971). The epidemiologic transition: a theory of the epidemiology of population change. The Milbank Memorial Fund Quarterly, 49(4, Pt. 1), 509-538

Omran A.R. (1998). The epidemiologic transition theory revisited thirty years later. World Health Statistics Quarterly, 51(2-4), 99-119

Pavlik Z. (1964). Nástin populaĉniho vývoje svéta. Praha: NCHAV.

Pavlik Z. (1982). Rewolucja demograficzna jako olgólna praviwidlowość rozwoju ludności. Warszawa.

Preston S.H., Keyfitz N., Schoen R. (1972). Causes of Death: Life Tables for National Population. New York: Seminar Press, Inc.

Robine J.-M. (2001). Redefining the stages of the epidemiological transition by a study of the dispersion of life spans: The case of France. Population: An English Selection, 13(1), 173193.

Rogers R., Hackenberg R. (1987). Extending epidemiologic transition theory: A New Stage. Social biology, 34(3-4), 234-243.

[Terris M.] (1972). The epidemiologic revolution. Editorials. American Journal of Public Health, 62(11): 1439-1441.

Terris M. (1976). The epidemiologic revolution, national health insurance and the role of health departments. American Journal of Public Health, 66(12), 1155-1164.

Todd E. (1990). La chute finale. Essai sur la décomposition de la sphère Soviétique. Nouvelle édition augmentée. Paris: Robert Laffont.

UN WPP-2019 (2019). Population Division of the Department of Economic and Social Affairs of the UN Secretariat. World Population Prospects 2019, Online Edition. POP/DB/WPP/Rev.2019/MORT/F01-1.

Van de Kaa D.J. (1987). Europe's second demographic transition. Population Bulletin, 42, 1

Van de Kaa D.J. (2010). Demographic transitions. In Zeng Yi. (Ed.), Encyclopedia of life support systems (EOLSS). Demography (Vol. 1, pp. 65-103). Eolss Publishers. Oxford, UK.

Vishnevsky A.G., Shkolnikov V.M., Vassin S.A. (1991). Epidemiological transition in the USSR as mirrored by regional differences. Genus, XLVII, 3-4, 79-100.

Weisz G., Olszynko-Gryn J. (2009). The Theory of Epidemiologic Transition: the origins of a citation classic. Journal of the History of Medicine and Allied Sciences, 65(3), 287-326. DOI:10.1093/jhmas/jrp058

WHO (2018). Noncommunicable diseases country profiles 2018. Geneva: World Health Organization.

WHO Mortality Database.

World Mortality Report (2019). UN Department of Economic and Social Affairs, Population Division. CD-ROM. POP/DB/WMR/Rev.2019/1/FA1 


\title{
EPIDEMIOLOGIC TRANSITION
}

\section{AND ITS INTERPRETATIONS}

\section{ANATOLY VISHNEVSKY}

\begin{abstract}
A critical analysis of A. Omran's theory of epidemiologic transition (ET) and of its various interpretations. The periodization of ET proposed by Omran is called into question, and the differentiation of the two "epidemiological revolutions" by M. Terris is compared with it. The paramount historical importance of ET as a trigger and an integral part of the demographic transition as a whole is noted. Disagreement with the interpretation of ET as an integral part of the "health transition" is substantiated. The concept of the "cardiovascular revolution" is contested. A method of graphical representation of ET is proposed and the criteria for its completion are discussed. Disagreement with ideas about the "first", Neolithic, and "third", expected in the future, ET, as well as about a "reverse" ET is substantiated. Problems with "catching up" ET in the less developed countries are considered.
\end{abstract}

Key words: epidemiologic transition, epidemiologic revolution, demographic transition, health transition, stages of epidemiologic transition, cardiovascular revolution, probability of death, mean age at death.

Anatoly Vishnevsky (avishnevsky@hse.ru), NATiOnal ReSEARCh University Higher School of Economics, RUSSIA.

THIS ARTICLE IS AN OUTPUT OF THE PROJECT "DEMOGRAPHIC AND MIGRATION PROCESSES IN RUSSIA IN THE HISTORICAL AND INTERNATIONAL CONTEXT IN THE LIGHT OF NEW METHODOLOGICAL APPROACHES" OF THE PROGRAM OF FUNDAMENTAL STUDIES, 2019.

DATE RECEIVED : JULY 2020.

\section{REFERENCES}

Acsadi G., Nemeskéri J. (1970). History of human life span and mortality. Budapest: Akadémiai kiadó.

Andreyev E.M., Vishnevsky A.G., Shaburov K.Yu. (1986). Prodolzhitel'nost' zhizni i prichiny smerti (Life expectancy and causes of death). In A.G. Volkov (Ed.), Demograficheskiye protsessy i ikh zakonomernosti (Demographic processes and their regularities) (pp. 110-130). Moscow: Mysl'. (In Russ.).

Barrett R., Kuzawa C.W., McDade T., Armelagos G.J. (1998). Emerging and re-emerging infectious diseases: the third epidemiologic transition. Annual review of anthropology, 27(1), 247-271.

Birabin J.-N. (2006). The History of the Human Population from the First beginnings to the Present Day. In G. Caselli, J. Vallin, G. Wunsh (Eds.), Demography: Analysis and Synthesis. A Treatise in Population Studies (Vol.3, Ch. 66). Academic Press.

Caldwell J.C. (2001). Population heath transition. Bulletin of the World Health Organization, 79, 159-160.

Caldwell J.C., Caldwell B.K. (2003). Was there a Neolithic mortality crisis? Journal of Population Research, 20(2), 153-168.

Chesnais J.-C. (1986). La transition démograhique. Etapes, formes, implications écpnomiques. PUF. 
Clausewitz K. (2017). O voyne. (Vom Krieg.) Moscow: Izdatel'stvo AST. (In Russ.).

Coleman D. (2004). Migration in the 21st century: a third demographic transition in the making? Plenary Address to the British Society for Population Studies Annual Conference, Leicester, 13 September 2004.

Davis K. (1944). Demographic fact and policy in India. Demographic Studies of Selected Areas of Rapid Growth. The Milbank Memorial Fund Quarterly, 22(3), 256-278.

Davis K. (1945).The World Demographic Transition. The Annals of the American Academy of Political and Social Science, 237, 1-11.

Davis K. (1963). The theory of change and response in modern demographic history. Population Index, 29(4), 345-366.

De Flora S., Quaglia A., Bennicelli C., and Vercelli M. (2005). The epidemiological revolution of the 20th century. The FASEB Journal, 19, 892-897.

Deevey E.S. (1960). The human population. Scientific American, 203(3), 194-205.

Defo B.K. (2014a). Beyond the 'transition' frameworks: the crosscontinuum of health, disease and mortality framework. Global Health Action, 7(1), 24804. URL: https://doi.org/10.3402/gha.v7.24804

Defo B.K. (2014b). Demographic, epidemiological, and health transitions: Are they relevant to population health patterns in Africa? Global Health Action, 7(1), 24804. URL: https://doi.org/10.3402/gha.v7.22443

Demoscope Weekly. Prilozheniye. Tabl. Koeffitsiyent mladencheskoy smertnosti. URL: http://www.demoscope.ru/weekly/app/app4009.php

Eggleston K.N., FuchsV.R. (2012). The new demographic transition: Most gains in life expectancy now realized late in life. Journal of Economic Perspectives, 26(3), 137-156.

Fihel A., Pechholdova M. (2017). Between 'Pioneers' of the Cardiovascular Revolution and Its 'Late Followers': Mortality Changes in the Czech Republic and Poland Since 1968. Eur J Population, 33, 651-678. URL: https://doi.org/10.1007/s10680-017-9456-y

Freedman R. (Ed.) (1964). Population: The Vital Revolution. Garden City, New York: Doubleday \& Co.

Frenk J., Bobadilla J.L., Sepulveda J., Cervantes M.L. (1989). Health transition in middleincome countries: New challenges for health care. Health Policy and Planning, 4(1): 29-39. DOI: $10.1093 /$ heapol/4.1.29

Frenk J., Bobadilla J.L., Stern C., Frejka T., Lozano R. (1991). Elements for a theory of the health transition. Health Transition Review, 1(1), 21-38.

Gavrilov L.A. (1984). Sushchestvuyet li predel prodolzhitel'nosti zhizni organizmov? (Is there a limit to the lifespan of organisms?). Biophysics, 29(5), 908-909. (In Russ.).

Gavrilov L.A., Gavrilova N.S. (1986). Biologiya prodolzhitel'nosti zhizni: kolichestvennyye aspekty (Life span biology: quantitative aspects). Moscow: Nauka. (In Russ.).

Human Cause-of-Death Database. French Institute for Demographic Studies (France) and Max Planck Institute for Demographic Research (Germany). Available at www.causeofdeath.org

Kannisto V., Nieminen M., Turpeinen O. (1999). Finnish Life Tables since 1751. Demographic Research, 1. DOI: 10.4054/DemRes.1999.1.1.

Landry A. (2019). La révolution démographique. Études et essais sur les problèmes de la population. Paris: Ined Éditions. 
Livi Bachchi M. (2010). Demograficheskaya istoriya Evropy. (The populaton of Europe). Saint Petersburg: Aleksandriya. (In Russ.).

Mackenbach J.P. (1994). The epidemiologic transition theory. Journal of Epidemiology and Community Health, 48, 329-332.

McKeown T., Brown R.G., Record R.G. (1972). An interpretation of the modern rise of population in Europe. Population Studies, 26(3), 345-382.

Meslé F., Vallin J. (2002). La transition sanitaire : tendances et perspectives. In G. Caselli, J. Vallin, G. Wunsch (Eds.), Démographie : analyse et synthèse (V. III. Ch. 57). INED.

Meslé F., Vallin J. (2006). The health transition: Trends and prospects. In G. Caselli, J. Vallin, G. Wunsh (Eds.), Demography: Analysis and Synthesis. A Treatise in Population Studies (V.2, Ch. 57). Academic Press.

Notestein F.W. (1945). Population - the long view. In Th.W Schults (Ed.), Food for the world (37-57). Chicago University Press.

Olshansky S.J., Ault A. (1986). The fourth stage of the epidemiologic transition: The age of delayed degenerative diseases. The Milbank Quarterly, 64(3), 355-391.

Olshansky S.J., Carnes B., Rogers R.G., Smith L. (1997). Infectious diseases - new and ancient threats to world health. Population bulletin, 52, 2.

Omran A.R. (1971). The epidemiologic transition: a theory of the epidemiology of population change. The Milbank Memorial Fund Quarterly, 49 (4, Pt. 1), 509-538

Omran A.R. (1977). Epidemiologicheskiy aspekt teorii estestvennogo dvizheniya naseleniya. (Epidemiological aspect of the theory of the natural growth of population. Original title: The epidemiologic transition: a theory of the epidemiology of population change). In D.I. Valentey, A.P. Sudoplatov (Eds.), Problemy narodonaseleniya. O demograficheskikh problemakh stran Zapada (pp. 57-91). Moscow: Progress. (In Russ.).

Omran A.R. (1998). The epidemiologic transition theory revisited thirty years later. World Health Statistics Quarterly, 51(2-4), 99-119

Omran A.R. (2019). Teoriya epidemiologicheskogo perekhoda: vzglyad 30 let spustya. (The epidemiologic transition theory revisited thirty years later). Demograficheskoye obozreniye (Demographic Review), 6(1), 177-216. URL: https://doi.org/10.17323/demreview.v6i1.9117 (In Russ.).

Pavlik Z. (1964). Nástin populaĉniho vývoje svéta. (Outline of population development of the World). Praha: NCHAV.

Pavlik Z. (1979). Problemy demograficheskoy revolyutsii (Problems of demographic revolution). In A.G. Vishnevskiy, I.S. Kon (Eds.), Brachnost', rozhdayemost', sem ya za tri veka (Nuptiality, fertility, family during three centuries) (pp. 158-168). Moscow: Statistika. (In Russ.).

Pavlik Z. (1982). Rewolucja demograficzna jako olgólna praviwidlowość rozwoju ludności. Warszawa.

Payevskiy V.V. (1970). Tablitsy smertnosti naseleniya SSSR (Mortality tables of the population of the USSR). In A.M. Merkov (Ed.), Voprosy demograficheskoy i meditsinskoy statistiki (Izbrannyye proizvedeniya) (Demographic and Health Statistics (Selected Works), (pp. 228307).Moscow: Statistika.

Preston S.H., Keyfitz N., Schoen R. (1972). Causes of Death: Life Tables for National Population. New York: Seminar Press, Inc. 
Robine J.-M. (2001). Redefining the stages of the epidemiological transition by a study of the dispersion of life spans: The case of France. Population: An English Selection, 13(1), 173193.

Rogers R., Hackenberg R. (1987). Extending epidemiologic transition theory: A New Stage. Social biology, 34(3-4), 234-243.

Semenova V.G. (2005) Obratnyy epidemiologicheskiy perekhod v Rossii (Reversal epidemiological transition in Russia). Moscow: TSSP. (In Russ.).

Shnirel'man V.A. (1986). Demograficheskiye i etnokul'turnyye protsessy epokhi pervobytnoy rodovoy obshchiny (Demographic and ethnocultural processes of the era of the primitive tribal community). In Bromley YU.V. (Ed.), Istoriya pervobytnogo obshchestva. Epokha pervobytnoy rodovoy obshchiny (The history of primitive society. The era of the primitive tribal community) (pp. 427-489). Moscow: Nauka. (In Russ.).

[Terris M.] (1972). The epidemiologic revolution. Editorials. American Journal of Public Health, 62(11): 1439-1441.

Terris M. (1976). The epidemiologic revolution, national health insurance and the role of health departments. American Journal of Public Health, 66(12), 1155-1164.

Todd E. (1990). La chute finale. Essai sur la décomposition de la sphère Soviétique. Nouvelle édition augmentée. Paris: Robert Laffont.

UN WPP-2019 (2019). Population Division of the Department of Economic and Social Affairs of the UN Secretariat. World Population Prospects 2019, Online Edition. POP/DB/WPP/Rev.2019/MORT/F01-1.

Van de Kaa D.J. (1987). Europe's second demographic transition. Population Bulletin, 42, 1.

Van de Kaa D.J. (2010). Demographic transitions. In Zeng Yi. (Ed.), Encyclopedia of life support systems (EOLSS). Demography (Vol. 1, pp. 65-103). Eolss Publishers. Oxford, UK.

Vishnevsky A.G. (1973). Demograficheskaya revolyutsiya (Demographic revolution). Voprosy filosofii 2, 53-64. (In Russ.).

Vishnevsky A.G. (1976). Demograficheskaya revolyutsiya (Demographic revolution). Moscow: Statistika. (In Russ.). 238 p.

Vishnevsky A.G. (2017). Nereshennyye voprosy teorii demograficheskoy revolyutsii (Unsolved problems in the theory of demographic revolution). Naseleniye i ekonomika (Population and Ecnomics), 1(1), 3-21. (In Russ.).

Vishnevsky A.G. (2018). Demograficheskiy perekhod i gipoteza giperbolicheskogo rosta naseleniya (The demographic transition and the hypothesis of hyperbolic population growth). Demograficheskoye obozreniye (Demographic Review), 5(1), 64-105. URL: https://doi.org/10.17323/demreview.v5i1.7710 (In Russ.).

Vishnevsky A.G., Shkol'nikov V.M., Vasin S.A. (1991). Epidemiologicheskiy perekhod i prichiny smerti v SSSR (Epidemiological transition in the USSR as mirrored by regional differences). Ekonomika i matematicheskiye metody (Economics and Mathematical Methods), 27(6), 1013-1021. (In Russ.).

Vishnevsky A.G., Shkolnikov V.M., Vassin S.A. (1991). Epidemiological transition in the USSR as mirrored by regional differences. Genus, XLVII, 3-4, 79-100.

Vishnyatsky L.B. (2000). «Verkhnepaleoliticheskaya revolyutsiya»: geografiya, khronologiya, prichiny. («The Upper Paleolithic Revolution»: its Geography, Chronology, and Causes). Stratum Plus, Arkheologiya i kul'turnaya antropologiya, 245-271. (In Russ.). 
Weisz G., Olszynko-Gryn J. (2009). The Theory of Epidemiologic Transition: the origins of a citation classic. Journal of the History of Medicine and Allied Sciences, 65(3), 287-326. DOI:10.1093/jhmas/jrp058

WHO (2018). Noncommunicable diseases country profiles 2018. Geneva: World Health Organization.

WHO Mortality Database.

World Mortality Report (2019). UN Department of Economic and Social Affairs, Population Division. CD-ROM. POP/DB/WMR/Rev.2019/1/FA1 